OPEN ACCESS

Edited by:

Eugenio Barone,

Sapienza University of Rome, Italy

Reviewed by:

Joana M. Gaspar

Universidade Federal de Santa

Catarina, Brazil

Marinette Van Der Graaf,

Radboud University Nijmegen Medical

Centre, Netherlands

*Correspondence:

João M. N. Duarte

joao.duarte@med.lu.se

Specialty section:

This article was submitted to

Neurodegeneration,

a section of the journal

Frontiers in Neuroscience

Received: 02 November 2018 Accepted: 17 December 2018

Published: 09 January 2019

Citation:

Duarte JMN, Skoug C, Silva HB,

Carvalho RA, Gruetter $R$ and Cunha RA (2019) Impact of Caffeine

Consumption on Type 2

Diabetes-Induced Spatial Memory Impairment and Neurochemical

Alterations in the Hippocampus.

Front. Neurosci. 12:1015.

doi: 10.3389/fnins.2018.01015

\section{Impact of Caffeine Consumption on Type 2 Diabetes-Induced Spatial Memory Impairment and Neurochemical Alterations in the Hippocampus}

\author{
João M. N. Duarte ${ }^{1,2,3,4 *}$, Cecilia Skoug ${ }^{3,4}$, Henrique B. Silva ${ }^{1}$, Rui A. Carvalho ${ }^{5}$, \\ Rolf Gruetter ${ }^{2,6,7}$ and Rodrigo A. Cunha ${ }^{1,8}$ \\ 'CNC-Center for Neuroscience and Cell Biology, University of Coimbra, Coimbra, Portugal, ${ }^{2}$ Laboratory for Functional and \\ Metabolic Imaging, École Polytechnique Fédérale de Lausanne, Lausanne, Switzerland, ${ }^{3}$ Department of Experimental \\ Medical Science, Faculty of Medicine, Lund University, Lund, Sweden, ${ }^{4}$ Wallenberg Centre for Molecular Medicine, Lund \\ University, Lund, Sweden, ${ }^{5}$ Department of Life Sciences, Faculty of Science and Technology, University of Coimbra, \\ Coimbra, Portugal, ${ }^{6}$ Department of Radiology, University of Lausanne, Lausanne, Switzerland, ${ }^{7}$ Department of Radiology, \\ University of Geneva, Geneva, Switzerland, ${ }^{8}$ Faculty of Medicine, University of Coimbra, Coimbra, Portugal
}

Diabetes affects the morphology and plasticity of the hippocampus, and leads to learning and memory deficits. Caffeine has been proposed to prevent memory impairment upon multiple chronic disorders with neurological involvement. We tested whether long-term caffeine consumption prevents type 2 diabetes (T2D)-induced spatial memory impairment and hippocampal alterations, including synaptic degeneration, astrogliosis, and metabolic modifications. Control Wistar rats and Goto-Kakizaki (GK) rats that develop T2D were treated with caffeine (1 $\mathrm{g} / \mathrm{L}$ in drinking water) for 4 months. Spatial memory was evaluated in a Y-maze. Hippocampal metabolic profile and glucose homeostasis were investigated by ${ }^{1} \mathrm{H}$ magnetic resonance spectroscopy. The density of neuronal, synaptic, and glial-specific markers was evaluated by Western blot analysis. GK rats displayed reduced Y-maze spontaneous alternation and a lower amplitude of hippocampal long-term potentiation when compared to controls, suggesting impaired hippocampal-dependent spatial memory. Diabetes did not impact the relation of hippocampal to plasma glucose concentrations, but altered the neurochemical profile of the hippocampus, such as increased in levels of the osmolites taurine $(P<0.001)$ and myo-inositol $(P<0.05)$. The diabetic hippocampus showed decreased density of the presynaptic proteins synaptophysin $(P<0.05)$ and SNAP25 $(P<0.05)$, suggesting synaptic degeneration, and increased GFAP $(P<0.001)$ and vimentin $(P<0.05)$ immunoreactivities that are indicative of astrogliosis. The effects of caffeine intake on hippocampal metabolism added to those of T2D, namely reducing myo-inositol levels $(P<0.001)$ and further increasing taurine levels $(P<0.05)$. Caffeine prevented 
T2D-induced alterations of GFAP, vimentin and SNAP25, and improved memory deficits. We conclude that caffeine consumption has beneficial effects counteracting alterations in the hippocampus of GK rats, leading to the improvement of T2D-associated memory impairment.

Keywords: insulin, adenosine, caffeine, neuroprotection, synaptic dysfunction, gliosis, glucose, metabolic profiling

\section{INTRODUCTION}

Metabolic syndrome and diabetes mellitus affect brain function and increase the risk of age-related cognitive impairment, vascular dementia, and Alzheimer's disease (Frisardi et al., 2010; Duarte, 2015; Moheet et al., 2015). Diabetes conditions are particularly associated with atrophy of the hippocampus (Convit et al., 2003; Gold et al., 2007). We and others have reported that experimental diabetic conditions cause synaptic degeneration (Duarte et al., 2006, 2009a, 2012), increase astrocytic reactivity and proliferation (Saravia et al., 2002; Baydas et al., 2003; Duarte et al., 2012), and change metabolism (Duarte et al., 2009a; Girault et al., 2018) in the hippocampus. As important as understanding the mechanisms of diabetes-induced hippocampal alterations leading to memory impairment, is the design of novel strategies to prevent such degeneration. The neuromodulation system operated by adenosine is altered in diabetes, with reduced density of adenosine $A_{1}$ receptors $\left(A_{1} R s\right)$ and increased density of adenosine $A_{2 A}$ receptors $\left(A_{2 A} R s\right)$ in membranes from the hippocampus (Duarte et al., 2006, 2012). Caffeine is a widely consumed non-selective antagonist of adenosine receptors (Fredholm et al., 1999), and both caffeine and selective adenosine $\mathrm{A}_{2 \mathrm{~A}} \mathrm{R}$ antagonists affect performance in learning and memory tasks (Takahashi et al., 2008; Cunha, 2016) and afford neuroprotection upon chronic brain insults (Cunha, 2005). In addition, caffeine may reduce the risk of developing glucose-intolerance and diabetes severity (e.g., van Dam and Hu, 2005; Greenberg et al., 2006; Higdon and Frei, 2006). We previously reported that caffeine consumption ameliorates diabetes-induced hippocampal degeneration and prevents diabetes-associated memory deficits in insulin-deficient rats (Duarte et al., 2009a) and in a mouse model of obesityassociated type 2 diabetes (T2D) (Duarte et al., 2012). The different etiology of lean T2D prompted us to investigate

\footnotetext{
Abbreviations: aCSF, artificial cerebrospinal fluid; Ala, alanine; Asc, ascorbate; Asp, aspartate; BBB, blood-brain-barrier; $\beta \mathrm{HB}, \beta$-hydroxibutyrate; CADO, 2-chloroadenosine; $\mathrm{CMR}_{\mathrm{glc}}$, cerebral metabolic rate of glucose consumption; Cr, creatine; CRLB, Cramér-Rao lower bound; DPCPX, 1,3-dipropyl-8cyclopentylxanthine; ELISA, enzyme-linked immunosorbent assay; fEPSP, field excitatory postsynaptic potential; GABA, $\gamma$-aminobutyrate; GFAP, glial fibrillary acidic protein; GK, Goto-Kakizaki; Glc, glucose; Gln, glutamine; Glu, glutamate; GPC, glycerophosphocholine; GSH, glutathione; I/O, input/output; Ins, myoinositol; Lac, lactate; LTP, long-term potentiation; MAP2, microtubule-associated protein type 2; MRS, magnetic resonance spectroscopy; NAA, $N$-acetylaspartate; NAAG, N-acetylaspartatylglutamate; NMR, nuclear magnetic resonance; PCho, phosphocholine; PCr, phosphocreatine; PE, phosphoethanolamine; PSD95, postsynaptic density protein of $95 \mathrm{kDa}$; SCH58261, 2-(2-furanyl)-7(2-phenylethyl)-7H-pyrazolo[4,3-e][1,2,4] triazolo[1,5-c]pyrimidin-5-amine; scyllo, scyllo-inositol; SNAP25, synaptosome-associated protein of $25 \mathrm{kDa}$; STZ, streptozotocin; Tau, taurine; VOI, volume of interest.
}

the effect of long-term caffeine intake on alterations in the hippocampus of Goto-Kakizaki (GK) rats, an animal model of non-obese T2D that was produced by selective breeding of nondiabetic Wistar rats which displayed high plasma glucose levels in oral glucose tolerance tests (Girault et al., 2018, and references therein). In this study, we tested the hypothesis that caffeine exposure ameliorates T2D-induced alterations of hippocampal metabolism, degeneration of synapses and astrogliosis, as well as concomitant spatial memory impairment.

\section{METHODS}

\section{Animals}

Animals were handled according to Swiss and Portuguese guidelines for the use of experimental animals, and authorized by the respective local ethics committees (EXPANIM-SCAV and ORBEA). Male GK rats, which spontaneously develop insulin resistance, and control Wistar-Hannover-Galas rats were obtained from Taconic (Lille Skensved, Denmark), or from the colony kept at the animal house of the Faculty of Medicine of the University of Coimbra (for electrophysiology recordings). We used a total of $22 \mathrm{GK}$ rats and 22 Wistar rats. All the animals were maintained with food and water ad libitum. When tested, caffeine was administered in the drinking water at $1 \mathrm{~g} / \mathrm{L}$ from 2 to 6 months of age ( 4 month period). Thus, the present experimental design included four animal groups: control Wistar, caffeinetreated Wistar, diabetic GK, and caffeine-treated GK. Body weight and caffeine consumption were monitored throughout the treatment period. Glycaemia was measured monthly in a $2 \mu \mathrm{L}$ blood sample collected by tail pricking, using a glucose oxidasebased glucometer (Ascencia Contour, Bayer, Switzerland). At 2 and 4 months of caffeine exposure, blood samples $(100 \mu \mathrm{L})$ were taken from the tail vein under brief isoflurane anesthesia $(2 \%$ in oxygen) for determination of serum caffeine and/or insulin concentrations.

\section{Behavioral Tasks}

Exploratory behavior and locomotor activity were evaluated in a square open-field arena of $34 \times 34 \mathrm{~cm}$ with $30 \mathrm{~cm}$ high, which was divided in 4 squares of $17 \times 17 \mathrm{~cm}$. The animals were placed in the central area of the arena and allowed to explore it over $5 \mathrm{~min}$ in the dark. The number of crossings of the squares and the number of rearing movements with forepaws were recorded. Rearing with the forepaws pressed against the walls was not considered.

Spontaneous alternation was observed in a Y-maze constructed in black Plexiglas, with three arms measuring $35 \mathrm{~cm}$ long, $9 \mathrm{~cm}$ wide and $30 \mathrm{~cm}$ height, and converging to equal 
angles, which was placed in a dim-illuminated room (12 lux) with large visual cues hanged on the walls. The animals were placed at the bottom of one arm of the Y-maze and allowed to explore freely all three arms for a single $8 \mathrm{~min}$ session in the dark. The measured spontaneous alternation behavior was used to assess hippocampal-dependent spatial memory (Lalonde, 2002). If the rat remembers the arm it has just explored, it will therefore enter one of the other arms of the maze. Complete spontaneous alternations were defined as successive entries into the three arms, and were expressed as fraction of the possible alternations in the respective test. In addition to the open field test, the number of entries in the arms of the maze also allowed to access locomotor activity and exploratory behavior of the tested rats.

\section{Localized ${ }^{1} \mathrm{H}$ Magnetic Resonance Spectroscopy (MRS)}

Rats were anesthetized with $2 \%$ isoflurane (Attane, Minrad, USA) in oxygen (PanGas, Ecublens, Switzerland), and then intubated and ventilated with a pressure-driven ventilator (MRI1, CWE incorporated, PA, USA). Catheters were placed into the femoral artery for monitoring blood gases, glucose and blood pressure, and into the femoral vein for infusion of saline solutions containing $\alpha$-chloralose (Acros Organics, Geel, Belgium) or D-glucose (Sigma-Aldrich, Switzerland). Rats were placed in a home-built holder that ensures a fixed and stable position of the skull for extended scanning times. Body temperature was maintained around $37.5^{\circ} \mathrm{C}$ with a warm water circulation system based on the feedback from a rectal temperature probe. Temperature, arterial blood pressure, heart rate, and respiratory rate were continuously monitored with an animal monitoring system (SA Instruments, NY, USA). Before inserting the animal in the bore of the magnet, anesthesia was switched to $\alpha$ chloralose (intravenous bolus of $80 \mathrm{mg} / \mathrm{kg}$, and continuous infusion of $25 \mathrm{mg} / \mathrm{kg} / \mathrm{h})$. D-glucose [20\% (w/v) solution] was infused at a rate adjusted based on the concomitantly measured arterial plasma glucose concentrations to achieve stable targeted glycaemia levels. NMR measurements were performed after each glucose level had been stable for at least $15 \mathrm{~min}$ (Duarte and Gruetter, 2012). Arterial $\mathrm{pH}$ and pressures of $\mathrm{O}_{2}$ and $\mathrm{CO}_{2}$ were measured using a blood gas analyser (AVL Compact 3, Diamond Diagnostics, MA, USA). Concentration of glucose in arterial plasma samples was quantified by the glucose oxidase method, using a multi-assay analyser (GM7 Micro-Stat, Analox Instruments, UK).

All experiments were carried out as previously described (Duarte et al., 2009a) using a Varian INOVA spectrometer (Agilent Technologies, Palo Alto, CA, USA) interfaced to an actively-shielded $9.4 \mathrm{~T}$ magnet with a $31 \mathrm{~cm}$ horizontal bore (Magnex Scientific, Abingdon, UK), and a homebuilt $10 \mathrm{~mm}$ ${ }^{1} \mathrm{H}$ quadrature surface coil. The rat brain was positioned in the isocentre of the magnet and located with fast-spin-echo images with $5 \mathrm{~s}$ repetition time, effective echo time of $52 \mathrm{~ms}$ and echo train length of 8 . Shimming was performed with FAST(EST)MAP (Gruetter and Tkáč, 2000), and ${ }^{1} \mathrm{H}$ NMR spectra were acquired from a volume of interest (VOI) of $18 \mu \mathrm{L}$ placed in the left dorsal hippocampus using SPECIAL spectroscopy, with echo time of $2.8 \mathrm{~ms}$ and repetition time of $4 \mathrm{~s}$ (Mlynárik et al., 2006). Spectra were analyzed using LCModel (Stephen Provencher Inc., Oakville, Ontario, Canada), including a macromolecule spectrum in the database, as previously described (Mlynárik et al., 2006; Duarte et al., 2009a). The unsuppressed water signal measured from the same VOI was used as an internal reference (assuming the existence of $80 \%$ of water in the brain tissue) for the absolute quantification of the following metabolites: glucose (Glc), ascorbate (Asc), phosphoethanolamine (PE), creatine $(\mathrm{Cr})$, phosphocreatine (PCr), myo-inositol (Ins), taurine (Tau), $N$-acetylaspartate (NAA), aspartate (Asp), glutamate (Glu), glutamine (Gln), $\gamma$-aminobutyrate (GABA), alanine (Ala), lactate (Lac), $\beta$-hydroxybutyrate $(\beta \mathrm{HB})$, glycerophosphocholine (GPC), phosphocholine (PCho), glutathione (GSH), $N$ acetylaspartylglutamate (NAAG), scyllo-inositol (scyllo). The Cramér-Rao lower bound (CRLB) was provided by LCModel as a measure of the reliability of the apparent metabolite concentration quantification. CRLBs above $30 \%$ were systematically associated to scyllo-inositol, which was thus not used for further analyses. The remaining metabolites were quantified with CRLBs below $30 \%$.

\section{Determination of Glucose Transport Kinetics}

The determination of hippocampal glucose by MRS in vivo as function of plasma glucose was used to estimate kinetic parameters of glucose transport across the blood-brain-barrier (BBB). Steady-state brain glucose transport kinetics was modeled with a four-state conformational model that accounts for reversibility and trans-acceleration of the glucose carrier (Duarte et al., 2009b). Hippocampal glucose at steady-state was fitted to the following equation

$$
\mathrm{G}_{\text {hipp }}=\mathrm{V}_{\mathrm{d}} \frac{\left(\frac{\mathrm{T}_{\max }}{\mathrm{CMR}_{\mathrm{glc}}}-1\right) \mathrm{G}_{\mathrm{p}}-\mathrm{K}_{\mathrm{t}}}{\frac{\mathrm{T}_{\max }}{\mathrm{CMR}_{\mathrm{glc}}}+1+\frac{\mathrm{G}_{\mathrm{p}}}{\mathrm{K}_{\mathrm{ii}}}}
$$

where $G_{\text {hipp }}$ and $G_{p}$ are the concentrations of glucose in the hippocampus (in $\mu \mathrm{mol} / \mathrm{g}$ ) and plasma (in $\mathrm{mmol} / \mathrm{L}$ ), respectively. $\mathrm{CMR}_{\mathrm{glc}}$ is the cerebral metabolic rate of glucose. $\mathrm{T}_{\max }$ denotes the apparent maximal transport rate across the BBB ( $\mu \mathrm{mol} / \mathrm{g} / \mathrm{min}$ ), $\mathrm{K}_{\mathrm{t}}$ and $\mathrm{K}_{\mathrm{ii}}$ denote the apparent Michaelis and iso-inhibition constants (in $\mathrm{mmol} / \mathrm{L}$ ), $V_{\mathrm{d}}=0.77 \mathrm{~mL} / \mathrm{g}$ is the volume of the physical distribution space of glucose in the hippocampus (see Duarte et al., 2009b for details).

\section{Western Blot Analysis}

Immediately after the MRS experiment, rats were decapitated, the brain was rapidly removed, and the hippocampus dissected. Whole membranes and synaptosomes (i.e., synaptic-enriched) membranes were prepared (Rebola et al., 2005; Cunha et al., 2006), and Western blot analysis of proteins in these hippocampal membrane preparations was performed using previously detailed methods (Duarte et al., 2007; Kaster et al., 2015). Western blot analysis of $A_{2 A} R$ was carried out as detailed by Hurtado-Alvarado et al. (2016), using the avidin-biotin Vectastain Elite kit (Vector Laboratories, Burlingame, CA-USA) 
for immunoreactivity amplification. The primary antibodies against the synaptic protein synaptosome-associated protein of $25 \mathrm{kDa}$ (SNAP25; from Sigma, Sintra, Portugal), and against the glial fibrillary acidic protein (GFAP; from Sigma) were used at dilution of 1:5,000. Antibodies against synaptophysin, $\alpha$-tubulin and $\beta$-actin were purchased from Sigma and used at 1:10,000. Anti-postsynaptic density protein of $95 \mathrm{kDa}$ (PSD95; from Chemicon) was used at 1:20,000; anti-vimentin (Sigma) and anti-microtubule-associated protein type 2 (MAP2; from Santa Cruz Biotechnology, Santa Cruz, CA, USA) at 1:1,000. Antibodies against $\mathrm{A}_{1} \mathrm{R}$ (Affinity Bioreagents, Golden, CO-USA) and $\mathrm{A}_{2 \mathrm{~A}} \mathrm{R}$ (Abcam, Cambridge, $\mathrm{UK}$ ) were used at a dilution of $1: 600$.

\section{Electrophysiological Recordings}

Electrophysiological recordings of synaptic transmission and plasticity were performed in superfused hippocampal slices, as previously described (Costenla et al., 2011; Kaster et al., 2015; Silva et al., 2018). Briefly, a rat was deeply anesthetized with 2bromo-2-chloro-1,1,1-trifluoroethane (halothane; no reaction to handling or tail pinch, while still breathing) before decapitation. The brain was rapidly removed and cooled in an artificial cerebrospinal fluid (aCSF) solution containing (in mmol/L): 124 $\mathrm{NaCl}, 3 \mathrm{KCl}, 2 \mathrm{CaCl}_{2}, 1 \mathrm{MgCl}_{2}, 1.25 \mathrm{NaH}_{2} \mathrm{PO}_{4}, 10$ glucose, $26 \mathrm{NaHCO}_{3}, \mathrm{pH} 7.4 ; 290-310$ mOsm, gassed with 95\% $\mathrm{O}_{2}$, and $5 \% \mathrm{CO}_{2}$. Coronal hippocampal slices ( $400 \mu \mathrm{m}$ thick) were prepared with a manual Vibratome 1,500 sectioning system (Vibratome, Germany), and allowed to recover for $1 \mathrm{~h}$ at room temperature in a Harvard Apparatus resting chamber filled with gassed aCSF. Individual dorsomedial hippocampal slices were transferred to a submerged recording chamber and continuously superfused at a rate of $4 \mathrm{~mL} / \mathrm{min}$ with gassed aCSF kept at $30.5^{\circ} \mathrm{C}$. A bipolar concentric stimulation electrode (SNE-100; Kopf, Germany) was placed over the Schaffer fibers delivering rectangular pulses $(550 \mu \mathrm{A})$ of $0.1 \mathrm{~ms}$ duration applied with a Digitimer DS3 stimulator (Digitimer LTD, UK) once every $20 \mathrm{~s}$. The evoked field excitatory postsynaptic potentials (fEPSPs) were recorded through an extracellular borosilicate microelectrode filled with $4 \mathrm{~mol} / \mathrm{L} \mathrm{NaCl}$ (2-5 $\mathrm{M} \Omega$ resistance) placed in the stratum radiatum of the CA1 area, coupled to an ISO-80 amplifier (World Precision Instruments, Hitchin, UK). Averages of four consecutive responses acquired with a $1 \mathrm{kHz}$ cut-off were digitalized and continuously monitored on a personal computer with the WINLTP 1.1 program (Anderson and Collingridge, 2001) to quantify the initial slope of the averaged fEPSPs, used to estimate the effect of drugs, added to the superfusion solution.

After obtaining a stable baseline, we first carried out an input/output curve to select a stimulus intensity triggering $40-50 \%$ of the maximal amplitude. We then tested the effects of 2-chloroadenosine (CADO, the closest and chemically stable analog of adenosine; from Tocris, Bristol, $\mathrm{UK}$ ) and 1,3-dipropyl-8-cyclopentylxantine (DPCPX, a selective antagonist of adenosine $A_{1} R$; from Tocris) on basal synaptic transmission. Alternatively, we tested the effect of 2-(2-furanyl)-7-(2-phenylethyl)-7H-pyrazolo[4,3e] $[1,2,4]$ triazolo[1,5-c]pyrimidin-5-amine (SCH58261, a selective antagonist of adenosine $\mathrm{A}_{2 \mathrm{~A}} \mathrm{R}$; from Sigma) on longterm potentiation (LTP). LTP was induced with a high-frequency train $(100 \mathrm{~Hz}$ for $1 \mathrm{~s})$ and was quantified as the percentage change between the fEPSP slopes $60 \mathrm{~min}$ after and $15 \mathrm{~min}$ before the train.

\section{Statistics}

Data was analyzed using ANOVA with two factors (diabetes and caffeine treatment). For the metabolic profile analysis, all metabolite concentrations were analyzed together with a multivariate ANOVA. Significant differences were considered for $P<0.05$. Multiple comparisons after ANOVA were performed with Fisher's least significant difference (LSD) tests upon significant diabetes effect or diabetes-caffeine interaction. Twotailed Student $t$-tests were used to compare caffeine intake and caffeine serum concentration between GK and Wistar rats, as well as the effects of CADO and DPCPX on synaptic transmission. Results are reported as mean \pm SEM unless otherwise stated.

\section{RESULTS}

To test the role of caffeine consumption in the prevention of diabetes-induced hippocampal alterations, GK rats and agematched controls were allowed to consume caffeine for 4 months, starting at 2 months of age. During the period when the rats had free access to $1 \mathrm{~g} / \mathrm{L}$ caffeine solution, body weight, and preprandial glycaemia were monitored and insulin plasma levels were quantified 2 months after starting caffeine intake and at the end of the experiment. GK rats were smaller than controls independent of caffeine consumption, which had no significant effect on body weight (diabetes $P=0.002$, caffeine $P=0.275$, interaction $P=0.794$; Figure 1A). T2D had a significant effect on fed glycaemia $(P<0.001)$, which was not impacted by caffeine treatment (caffeine $P=0.779$, interaction $P=0.935$; Figure 1B). Relative to controls, GK rats showed an increase in serum insulin concentration after 2 and 4 months of treatment $(P=0.002$ and $P=0.036$, respectively). At 4 months of treatment, caffeine prevented the diabetes-associated hyperinsulinemia (caffeine $P=0.212$, diabetes $P=0.240$, interaction $P=0.050$; Figure 1C). Caffeine intake was slightly lower in Wistar than GK rats, but not significantly different $(P=0.063$; Figure 1D). Serum levels of caffeine at the end of the treatment period were similar in diabetic and control rats $(P=0.558$; Figure 1E).

\section{Caffeine Consumption Prevents Spatial Memory Impairment in GK Rats}

Hippocampal-dependent spatial memory was tested in a Ymaze 2 days before MRS in vivo at 6 months of age, i.e., after 4 months of caffeine exposure. Both diabetes and caffeine treatment affected spatial memory performance in the Y-maze (diabetes $P=0.011$, caffeine $P=0.033$, interaction $P=0.549$ ). Post-hoc testing revealed that diabetes in GK rats caused a reduction of the spontaneous alternation in the Y-maze task when compared to controls $(-19 \pm 3 \% ; P<0.001$; Figure 2A), which was ameliorated by 4 months of caffeine consumption. GK rats also showed a significant reduction in the number of entries in the Y-maze arms, independently of caffeine intake (diabetes 

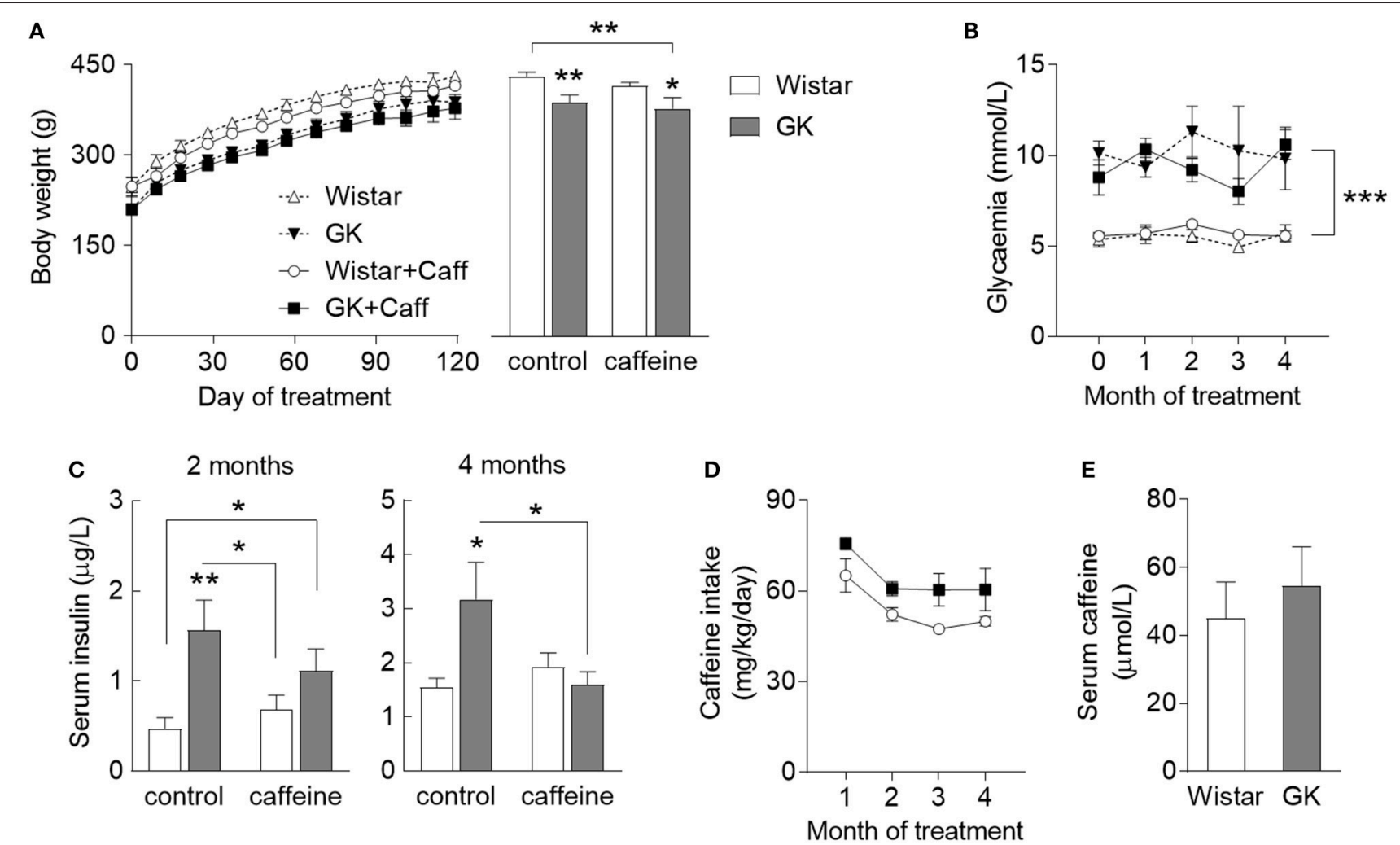

FIGURE 1 | Characteristics of diabetic GK rats (filed symbols/bars) and control Wistar rats (open symbols/bars), namely body weight (A) across the caffeine treatment period (line graph) and at the end of the study (bar graph), glycaemia (B), concentration in the serum insulin determined after 2 and 4 months of treatment (C), caffeine intake measured across the treatment period (D), and concentration of serum caffeine after 4 months of caffeine exposure (E). Caffeine (1 $\mathrm{g} / \mathrm{L})$ was provided through the drinking water for 4 months, starting at 2 months of age. Data are mean \pm SEM of 8 rats per group. Symbols represent LSD test results after ANOVA with either significant diabetes effect or significant diabetes-caffeine interaction: ${ }^{\star} P<0.05,{ }^{\star \star} P<0.01,{ }^{\star \star \star} P<0.001$ for GK vs. Wistar in the respective treatment group or as indicated.

$P=0.003$, caffeine $P=0.199$, interaction $P=0.546$; Figure $2 B$ ). Nevertheless, diabetes was not associated with exploratory or locomotor impairment as gauged by similar exploration of the open-field arena (Figures 2C,D). Interestingly, caffeine impacted the number of rearing events in the open-field test (caffeine $P=0.014$, diabetes $P=0.974$, interaction $P=0.974$ ), without impacting the number of crossing events between quadrants of the arena (caffeine $P=0.908$, diabetes $P=0.465$, interaction $P=0.113)$.

\section{Diabetes-induced Metabolic Alterations}

${ }^{1} \mathrm{H}$ spectra were acquired at 9.4 Tesla from the dorsal hippocampus of rats with half-height linewidths of $8-14 \mathrm{~Hz}$ and signal-to-noise ratios above 20 , as reported by the LCModel. By inspecting these representative spectra (Figure 3A), one notices increased resonances of taurine in the hippocampus of GK rats relative to controls. This was in fact the most prominent metabolic alteration present in this model of T2D (see statistics below). Nineteen metabolites were quantified under normoglycaemia for the four experimental groups (Figure 3B). Analysis with a multivariate ANOVA to the whole metabolic profile indicated significant effects of diabetes $(P=0.002)$ and caffeine $(P=0.028)$ without diabetes-caffeine interaction
( $P=0.493)$, which suggests cumulative effects of both factors. Furthermore, none of the levels of metabolites showed significant interaction between diabetes and caffeine in follow-up individual analyses.

Diabetes affected the concentration of taurine $(P<0.001)$, ascorbate $(P<0.001)$, creatine $(P=0.002)$, phosphocreatine $(P<0.001)$, glutamine $(P=0.041)$, myo-inositol $(P=0.011)$, lactate $(P=0.005)$, and glycerophosphorylcholine $(P<0.001)$. In post-hoc analyses comparing GK and Wistar rats in the absence of caffeine, GK rats only displayed significant increases in the levels of taurine $(+22 \pm 3 \%, P<0.001)$, ascorbate $(+20 \pm 9 \%, P=0.038)$, lactate $(+34 \pm 14 \%, P=0.035)$, and phosphocreatine $(+11 \pm 4 \%, P=0.028)$. Moreover, we observed a tendency for reduced creatine levels in GK rats $(-7$ $\pm 4 \%, P=0.080$ vs. Wistar), which resulted in a significant increase of phosphocreatine-to-creatine ratio $(\mathrm{PCr} / \mathrm{Cr}$; diabetes $P=0.004$, caffeine $P=0.150$, interaction $P=0.378$ ). High $\mathrm{PCr} / \mathrm{Cr}$ under normoglycaemia suggests that the hippocampus of GK rats is metabolically adapted to the diabetic condition in order to provide sufficient energy for basal oxidative metabolism.

On top of the effect of diabetes, caffeine consumption for 4 months had an effect on the concentration of creatine $(P=0.027)$, myo-inositol $(P<0.001), N$-acetylaspartylglutamate 

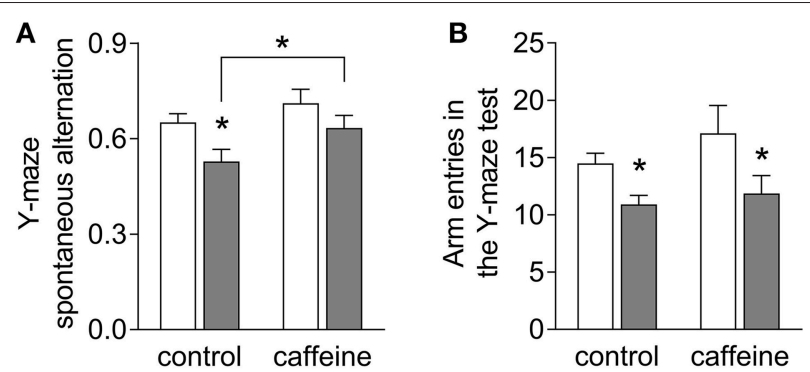

C

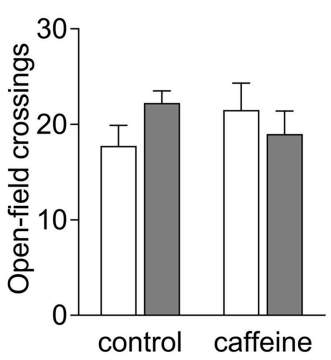

D

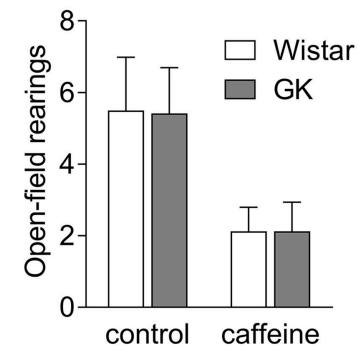

FIGURE 2 | Caffeine consumption improves spatial working memory deficits in diabetic GK rats. GK rats displayed reduced spontaneous alternation in the Y-maze, when compared to controls, but not if treated with caffeine for 4 months (A). The number of entries in the $Y$-maze arms was lower in GK compared to control rats irrespective of caffeine consumption (B). The number of crossings in the open-field arena was unaltered by diabetes or caffeine consumption (C), but the number of rearing events was reduced upon chronic caffeine consumption (D). Data are mean \pm SEM of 8 rats per group. Symbols represent LSD test results after ANOVA with either significant diabetes effect or significant diabetes-caffeine interaction: ${ }^{\star} P<0.05$ for GK vs. Wistar in the respective treatment group or as indicated.

$(P=0.036)$ and taurine $(P=0.023)$. Notably, when compared to untreated controls, Wistar rats consuming caffeine exhibited reduced myo-inositol $(-9 \pm 2 \%, P=0.002)$ and increased taurine $(+15 \pm 2 \%, P<0.001)$ concentrations in the hippocampus. Post-hoc analyses within the caffeine-treated rats revealed higher levels of ascorbate $(+35 \pm 9 \%, P=0.002)$, taurine $(+14 \pm 4 \%, P=0.004)$, $m y o$-inositol $(7 \pm 2 \%, P=0.006)$, and phosphocreatine $(7 \pm 3 \%, P=0.045)$ in GK than Wistar rats. Altogether, these results suggest that the caffeine-induced changes, namely in the osmolites myo-inositol and taurine, add to those induced by $\mathrm{T} 2 \mathrm{D}$.

\section{Hippocampal Glucose Homeostasis}

We have recently reported that diabetes impairs global glucose transport and consumption in the brain, without changes in the brain to plasma glucose levels (Girault et al., 2018). Since the hippocampus is particularly affected by T2D in experimental models, we measured hippocampal glucose concentration at several steady-state plasma glucose levels to test whether BBB transport of glucose in this region remains sufficient to feed metabolism. Physiology parameters measured during the periods of MRS were similar in all four experimental groups (Table 1). Glucose concentration in the hippocampus was similar for GK and control rats, and was dependent on plasma glucose levels (Figure 4). This indicates that the relation between glucose transport and consumption is not altered in the hippocampus of insulin-resistant GK rats, confirming previous observations in the whole brain (Girault et al., 2018). Kinetic parameters for hippocampal glucose transport estimated with the four-state conformational model were similar across the four experimental groups (Table 2). Indeed, neither T2D nor habitual caffeine consumption affected $\mathrm{T}_{\max } / \mathrm{CMR}_{\mathrm{glc}}$, suggesting that glucose transport at the BBB in our experimental conditions matches the glucose consumption needs in the hippocampus.

\section{Synaptic Alterations in the Hippocampus of GK Rats}

The putative degeneration of synapses was evaluated by quantifying the density of two presynaptic proteins in nerve terminal-enriched membrane preparations. As shown to occur in streptozotocin-induced diabetic rats (Duarte et al., 2006, 2009a) and NONcNZO10/Ltj diabetic mice (Duarte et al., 2012), the hippocampus of GK rats displayed synaptic degeneration, as suggested by reduced immunoreactivity of SNAP25 $(-23 \pm$ $5 \%, P=0.009, n=8$, Figure 5A) and synaptophysin $(-19$ $\pm 3 \%, P=0.007, n=5$, Figure 5B), when compared to control rats. Chronic caffeine consumption for 4 months did not significantly affect the immunoreactivity of these synaptic markers, whereas it prevented the T2D-induced reduction of SNAP25 (caffeine $P=0.587$, diabetes $P=0.176$, interaction $P=0.0162$; Figure 5A) but not synaptophysin immunoreactivity (caffeine $P=0.349$, diabetes $P=0.001$, interaction $P=0.681$; Figure 5B). To evaluate whether T2D also affected the postsynaptic compartment, we quantified the immunoreactivity of post-synaptic density-95 (PSD95), a prototypical postsynaptic marker. The immunoreactivity of PSD95 was not significantly altered in synaptic membranes of GK rats when compared to controls in the absence or presence of caffeine treatment (caffeine $P=0.719$, diabetes $P=0.053$, interaction $P=0.692$; Figure 5C). Furthermore, total membranes from the hippocampus of GK and control rats also displayed similar MAP2 immunoreactivity (caffeine $P=0.129$, diabetes $P=0.154$, interaction $P=0.915$; Figure 5D). Altogether these results suggest a main T2D-induced defect at presynaptic level.

\section{Caffeine Consumption Prevents Diabetes-Induced Astrogliosis}

Astrogliosis has been reported in several neurodegenerative diseases, including diabetes (e.g., Saravia et al., 2002; Baydas et al., 2003; Duarte et al., 2009a, 2012). This was now also found in the hippocampus of GK diabetic rats. Thus, when compared to controls, total hippocampal membranes prepared from GK rats exhibited increased immunoreactivity of GFAP $(+20 \pm$ $5 \%, P<0.001, n=8$; Figure $5 \mathrm{E})$ and vimentin $(+65 \pm 28 \%$, $P=0.010, n=5$, Figure 5F). While caffeine intake was devoid of significant effects on the measured glial proteins in control Wistar rats, it prevented T2D-induced increase in the immunoreactivity of both astroglial-specific proteins GFAP (caffeine $P=0.053$, diabetes $P=0.026$, interaction $P=0.003$, Figure 5E) and vimentin (caffeine $P=0.280$, diabetes $P=0.108$, interaction $P=0.030$, Figure 5F). 

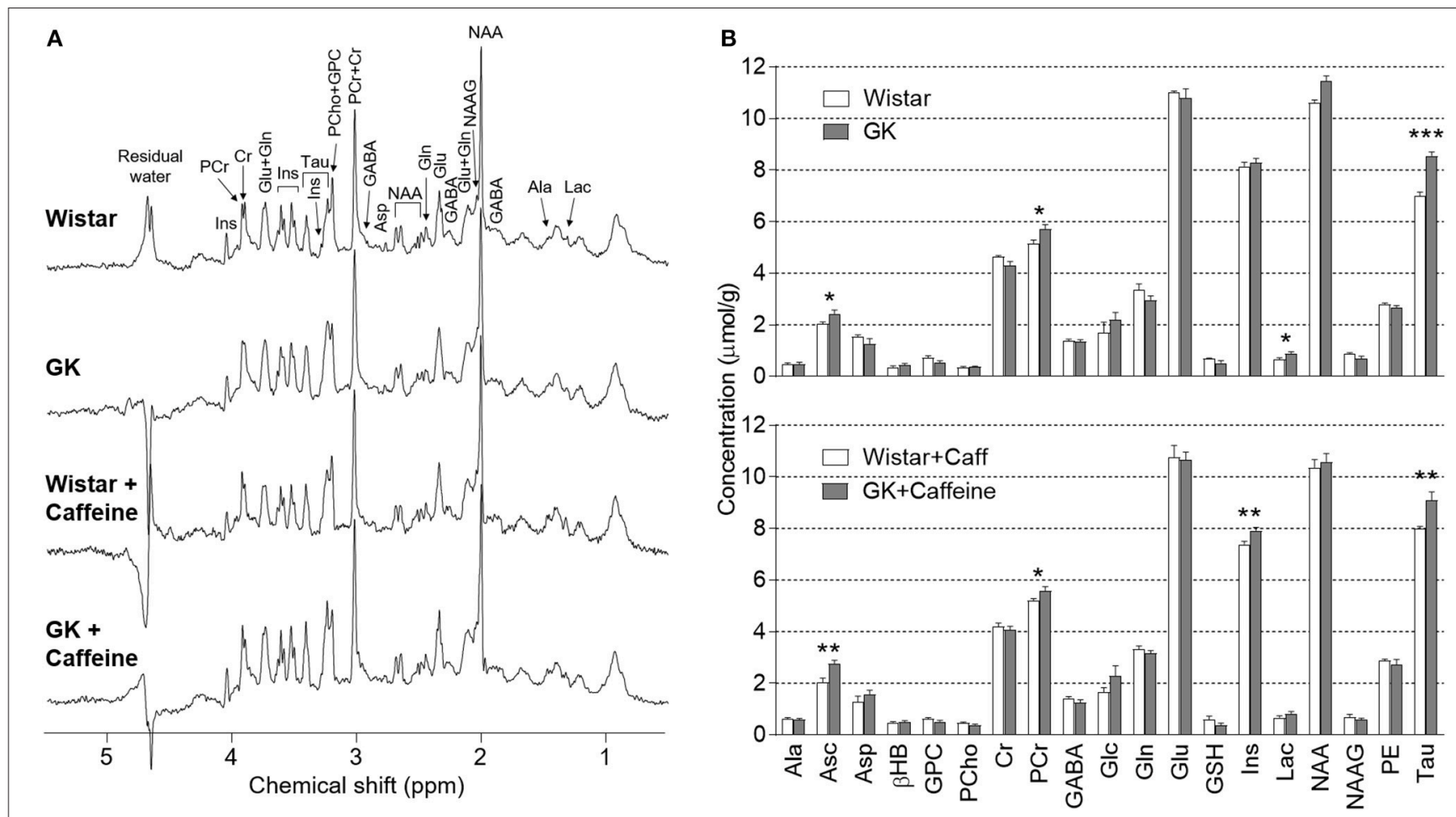

FIGURE 3 | Diabetes-induced metabolic alterations persisted upon caffeine treatment. (A) shows representative ${ }^{1} \mathrm{H}$ spectra acquired in vivo at $9.4 \mathrm{~T}$ from the dorsal hippocampus rats under normoglycaemia. An increase of taurine resonances at 3.25 and $3.42 \mathrm{ppm}$ in the spectra from GK rats is clearly visible. The spectra were measured by the SPECIAL sequence with echo time of $2.8 \mathrm{~ms}$, repetition time of $4 \mathrm{~s}, 640$ scans and in a volume of $18 \mu \mathrm{L}$. For resolution enhancement, a shifted Gaussian function ( $\mathrm{g} f=0.12$ and gsf $=0.05$ ) was applied before Fourrier transformation. Zero-phase but not baseline was corrected. (B) shows mean metabolite concentrations in the hippocampus of Wistar $(n=6)$, GK $(n=8)$, caffeine-treated Wistar $(n=7)$ and caffeine-treated GK $(n=8)$ rats, at plasma glucose below 8 $\mathrm{mmol} / \mathrm{L}$. None of the metabolite concentrations showed caffeine-diabetes interaction. Results from post-hoc tests on metabolite levels after significant diabetes effect or caffeine-diabetes interaction are represented by ${ }^{\star} P<0.05,{ }^{\star \star} P<0.01$, and ${ }^{\star \star \star} P<0.001$ for GK vs. Wistar in the respective treatment group.

\section{Altered Density of Adenosine $A_{1}$ and $A_{2 A}$ Receptors in the Hippocampus}

The density of adenosine receptors was evaluated by Western Blot in whole membranes and nerve terminal-enriched membranes prepared from the hippocampus. In synaptosomes, there was a significant interaction between effects of diabetes and caffeine on the density of $\mathrm{A}_{1} \mathrm{R}$ (interaction $P<0.001$, diabetes $P=0.539$, caffeine $P=0.002$, Figure 6A). When compared to controls, post-hoc analyses revealed a significant reduction of $\mathrm{A}_{1} \mathrm{R}$ immunoreactivity in $\mathrm{GK}$ rats $(-28 \pm 7 \%, P=0.014$, $n=8)$, which was reversed upon caffeine consumption $(+40$ $\pm 10 \%, P=0.002, n=8)$. In contrast, diabetes caused a significant increase in levels of $\mathrm{A}_{2 \mathrm{~A}} \mathrm{R}$ in synaptic membranes, independently of caffeine consumption (diabetes $P<0.001$, caffeine $P=0.919$, interaction $P=0.223$; Figure 6A). In the absence of caffeine, hippocampal synaptosomes from GK rats showed a $18 \pm 7 \%$ increase of $\mathrm{A}_{2 \mathrm{~A}} \mathrm{R}$ immunoreactivity $(P=0.031$, $n=3)$. Within caffeine treated rats, there was a T2D-induced increase of $\mathrm{A}_{2 \mathrm{~A}} \mathrm{R}$ immunoreactivity of $32 \pm 6 \% \quad(P=0.014$, $n=3)$. In total membranes, $\mathrm{T} 2 \mathrm{D}$ was associated to a major reduction of $\mathrm{A}_{1} \mathrm{R}$ levels (diabetes $P=0.006$, caffeine $P=0.210$, interaction $P=0.181$ ), which was significantly different from controls only in the absence of caffeine treatment $(-47 \pm 8 \%$, $P=0.005, n=6$; Figure 6B). In turn, the opposite effect was observed for $A_{2 A} R$ immunoreactivity, which increased in GK rats compared to controls in the absence $(+71 \pm 26 \%, P=0.046$, $n=2$ ) but not in the presence of caffeine treatment (diabetes $P=0.057$, caffeine $P=0.205$, interaction $P=0.232$ ). It should be noted however that the detection of changes on $A_{2 A} R$ density by Western blot suffered from technical challenges due to the known low immunoreactivity signal from the hippocampus of 6 month old rats (e.g., Rebola et al., 2003; Canas et al., 2009a). This is especially critical in total membranes from the rat hippocampus, in which the density of $\mathrm{A}_{2 \mathrm{~A}} \mathrm{R}$ is about half of that in synaptosomal membranes (e.g., Rebola et al., 2005; Duarte et al., 2006). Therefore, the present $A_{2 A} R$ density changes should be interpreted in a qualitative rather than quantitative manner.

\section{Altered Efficiency of Adenosine Receptors Controlling Hippocampal Synaptic Transmission and Plasticity}

The near superimposable input/output curves obtained in hippocampal slices from Wistar and GK rats ascertains that there were no changes in the density of excitatory inputs in Schaffer fibers CA1 pyramid synapses (Figure 7A), enabling a direct comparison of the efficiency of $\mathrm{A}_{1} \mathrm{R}$ and $\mathrm{A}_{2 \mathrm{~A}} \mathrm{R}$ to control synaptic transmission and plasticity. Thus, we tested the ability of $A_{1} R$ to control basal synaptic transmission 
TABLE 1 | Mean physiologic parameters measured at 5 different intervals of steady-state plasma glucose concentration in MRS experiments.

\begin{tabular}{|c|c|c|c|c|c|c|}
\hline \multicolumn{2}{|c|}{ Plasma glucose range (mM) } & \multirow{2}{*}{$\begin{array}{c}<8 \\
37.5 \pm 0.2\end{array}$} & \multirow{2}{*}{$\begin{array}{c}\text { 8-14 } \\
37.4 \pm 0.1\end{array}$} & \multirow{2}{*}{$\begin{array}{c}\text { 14-20 } \\
37.5 \pm 0.1\end{array}$} & \multirow{2}{*}{$\begin{array}{c}\text { 20-26 } \\
37.2 \pm 0.2\end{array}$} & \multirow{2}{*}{$\begin{array}{c}>\mathbf{2 6} \\
37.3 \pm 0.1\end{array}$} \\
\hline Body Temperature $\left({ }^{\circ} \mathrm{C}\right)$ & Control & & & & & \\
\hline & Caffeine & $37.5 \pm 0.2$ & $37.2 \pm 0.2$ & $37.3 \pm 0.1$ & $37.1 \pm 0.1$ & $37.4 \pm 0.1$ \\
\hline & GK & $37.0 \pm 0.1$ & $37.3 \pm 0.2$ & $37.2 \pm 0.3$ & $37.4 \pm 0.2$ & $37.0 \pm 0.1$ \\
\hline & GK + Caffeine & $37.5 \pm 0.1$ & $37.3 \pm 0.2$ & $37.5 \pm 0.2$ & $37.6 \pm 0.1$ & $37.2 \pm 0.1$ \\
\hline \multirow[t]{4}{*}{ Arterial pH } & Control & $7.34 \pm 0.01$ & $7.34 \pm 0.01$ & $7.34 \pm 0.01$ & $7.31 \pm 0.02$ & $7.33 \pm 0.03$ \\
\hline & Caffeine & $7.42 \pm 0.02$ & $7.38 \pm 0.01$ & $7.35 \pm 0.01$ & $7.35 \pm 0.01$ & $7.33 \pm 0.02$ \\
\hline & GK & $7.41 \pm 0.02$ & $7.40 \pm 0.02$ & $7.42 \pm 0.02$ & $7.40 \pm 0.01$ & $7.39 \pm 0.01$ \\
\hline & GK + Caffeine & $7.44 \pm 0.01$ & $7.45 \pm 0.01$ & $7.39 \pm 0.02$ & $7.39 \pm 0.02$ & $7.38 \pm 0.02$ \\
\hline \multirow[t]{4}{*}{$\mathrm{P}_{\mathrm{a}} \mathrm{CO}_{2}(\mathrm{~mm} \mathrm{Hg})$} & Control & $44.7 \pm 2.0$ & $44.7 \pm 1.6$ & $46.8 \pm 1.3$ & $44.9 \pm 1.9$ & $42.1 \pm 2.0$ \\
\hline & Caffeine & $39.9 \pm 2.9$ & $41.5 \pm 2.7$ & $45.7 \pm 3.9$ & $41.7 \pm 2.7$ & $41.4 \pm 2.9$ \\
\hline & GK & $39.0 \pm 3.4$ & $38.6 \pm 2.0$ & $37.2 \pm 2.7$ & $40.3 \pm 2.6$ & $43.2 \pm 2.3$ \\
\hline & GK + Caffeine & $35.7 \pm 1.7$ & $39.5 \pm 4.7$ & $38.9 \pm 3.0$ & $40.7 \pm 3.0$ & $40.1 \pm 1.3$ \\
\hline
\end{tabular}

Data is mean \pm SEM of 6 to 8 rats in each experimental group.

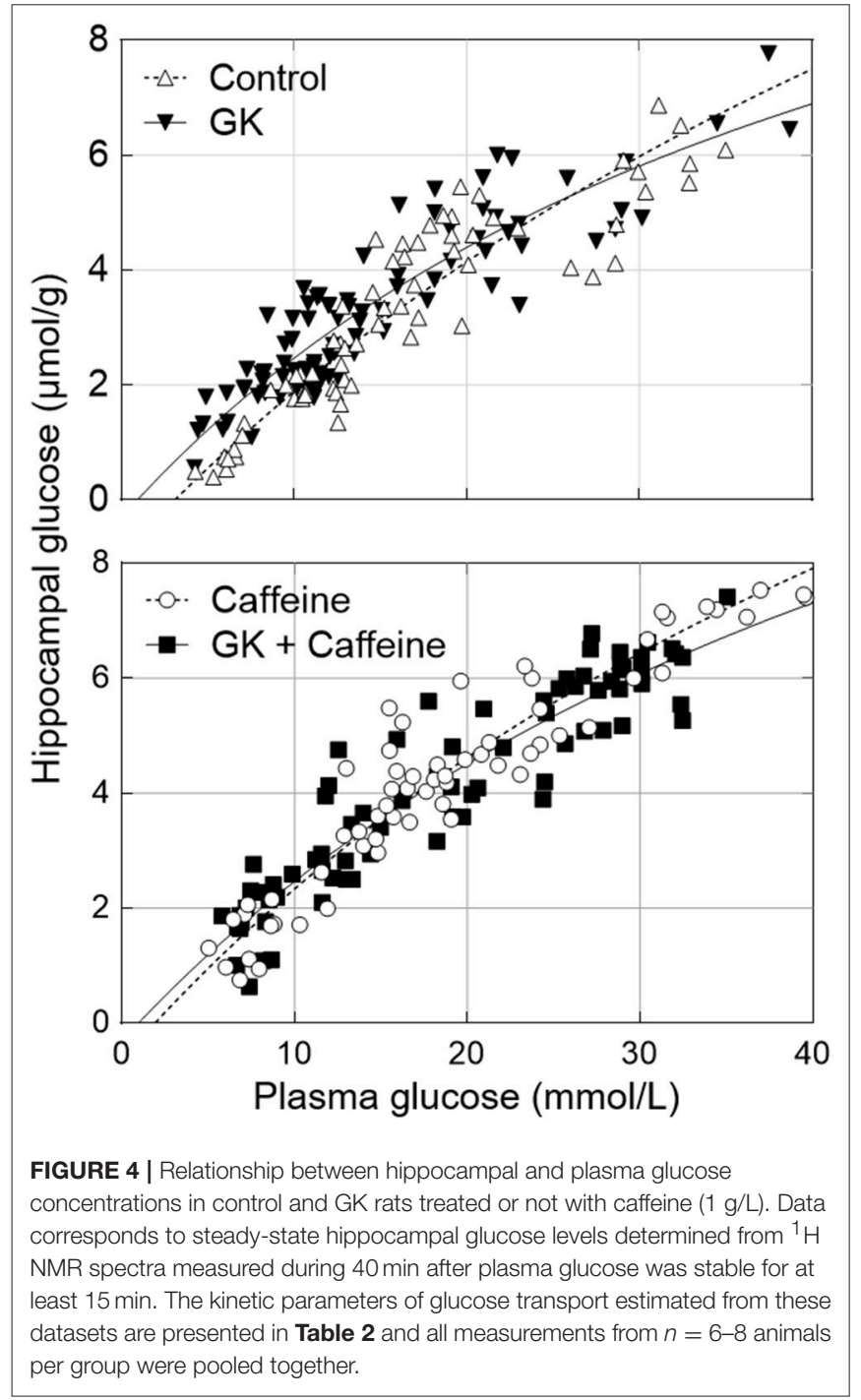

TABLE 2 | Apparent Michaelis-Menten constant $\left(K_{t}\right)$, iso-inhibition constant $\left(K_{i i}\right)$ and ratio of maximal transport rate $\left(T_{\max }\right)$ to cerebral glucose consumption rate $\left(\mathrm{CMR}_{\text {glc }}\right)$ for the glucose transport across the BBB, estimated with the 4-state conformational model from the relationship between hippocampal and plasma glucose concentrations in control, GK, caffeine-treated control, caffeine-treated GK rats (data in Figure 4).

\begin{tabular}{lccc}
\hline & $\mathbf{T}_{\mathbf{m a x}} / \mathbf{C M R}_{\mathbf{g l c}}$ & $\mathbf{K}_{\mathbf{t}}$ & $\mathbf{K}_{\mathrm{ii}}$ \\
\hline Control & $2.3(1.9-3.1)$ & $4.2(2.4-7.4)$ & $22.9(8.4-161.8)$ \\
GK & $2.5(2.0-4.7)$ & $1.5(0.0-8.2)$ & $12.9(3.3-55.0)$ \\
Caffeine-treated control & $2.5(1.9-4.3)$ & $2.9(0.1-10.4)$ & $19.1(5.0-201.9)$ \\
Caffeine-treated GK & $2.4(1.9-6.8)$ & $1.4(0.0-17.4)$ & $16.2(2.3-74.9)$
\end{tabular}

Values are mean (95\% confidence interval). Units of $K_{t}$ and $K_{i i}$ are $\mathrm{mmol} / \mathrm{L}, T_{\max } / C M R_{g l c}$ is adimensional.

(Costenla et al., 2011) and found that the closest chemical analog of adenosine, 2-chloroadenosine (CADO), triggered a similar concentration-dependent inhibition of synaptic transmission (Figure 7B). In fact, the estimated $\mathrm{EC}_{50}$ of $\mathrm{CADO}$ to inhibit synaptic transmission was $0.56 \mu \mathrm{mol} / \mathrm{L}$ (95\% confidence interval: $0.08-1.04 \mu \mathrm{mol} / \mathrm{L}, n=6)$ in slices from Wistar rats, which was similar $(P=0.833)$ to the $\mathrm{EC}_{50}$ values obtained in slices from GK rats $(0.61 \mu \mathrm{mol} / \mathrm{L}, 95 \%$ confidence interval: $0.23-1.00$ $\mu \mathrm{mol} / \mathrm{L}, n=6)$. We then investigated if there were changes in the levels of endogenous adenosine tonically controlling basal excitatory transmission (Costenla et al., 2011). A supra-maximal but selective concentration $(100 \mathrm{nmol} / \mathrm{L})$ of the $\mathrm{A}_{1} \mathrm{R}$ antagonist DPCPX (Sebastião et al., 2000) caused a greater disinhibition of hippocampal synaptic transmission in GK rats compared to Wistar rats $(P=0.006 ; n=6$; Figures $7 \mathrm{C}, \mathbf{D})$. This suggests a preserved efficiency of $\mathrm{A}_{1} \mathrm{R}$-mediated inhibition of synaptic transmission and higher levels of endogenous extracellular adenosine controlling synaptic transmission in GK rats.

We next compared synaptic plasticity in hippocampal slices from Wistar and GK rats to gauge the efficiency of $A_{2 A} R$ 


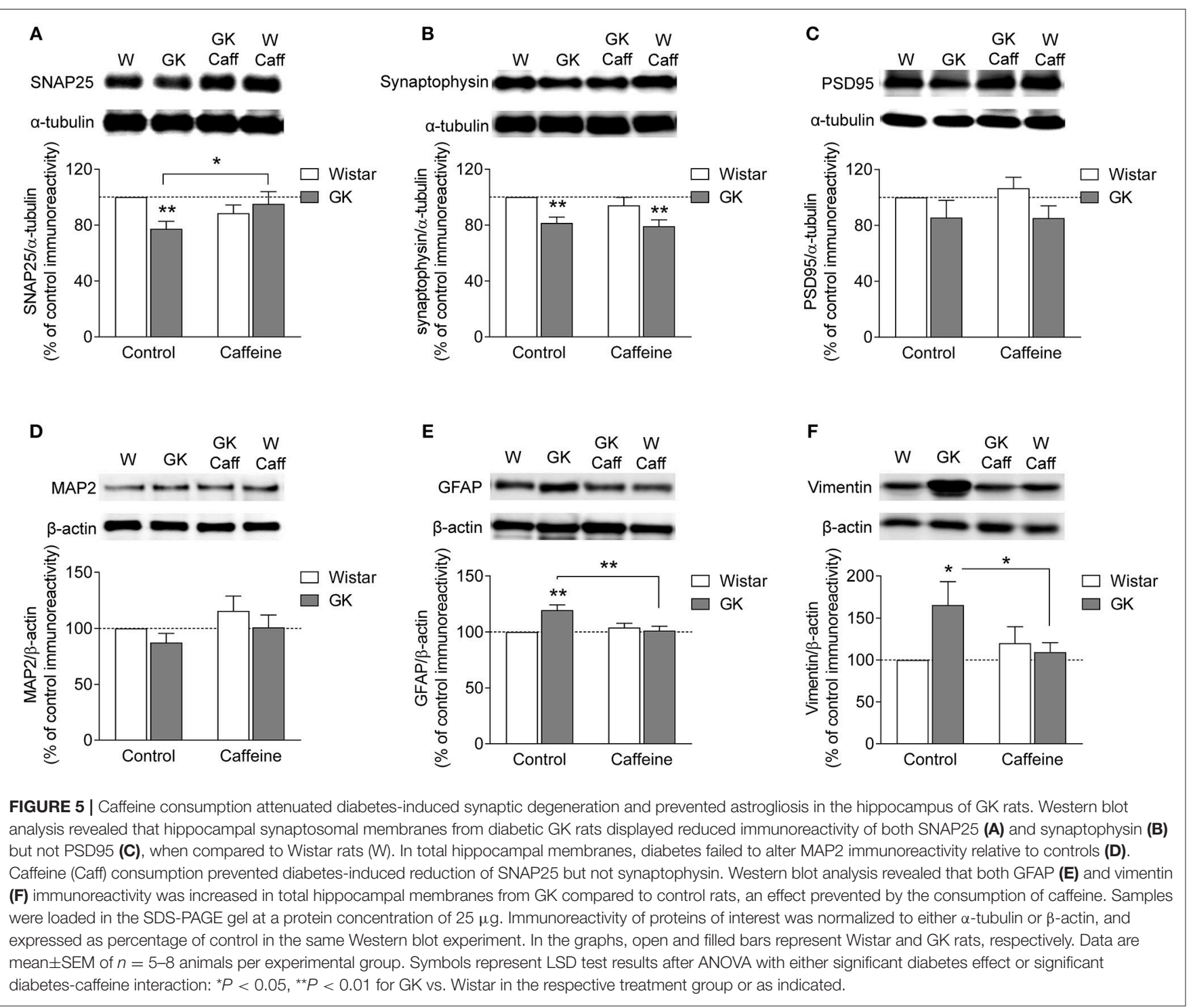

that selectively control hippocampal synaptic plasticity (Rebola et al., 2008; Costenla et al., 2011). The amplitude of long-term potentiation (LTP) was lower $(P=0.0004$, Figure 7E) in GK rats $(52 \pm 4 \%$ over baseline, $n=6)$ than in Wistar rats $(83$ $\pm 2 \%$ over baseline, $n=5$ ). The selective $\mathrm{A}_{2 \mathrm{~A}} \mathrm{R}$ antagonist SCH58261, used in a supramaximal and selective concentration of $50 \mathrm{nmol} / \mathrm{L}$ (Lopes et al., 2004), caused a discrete inhibition of LTP amplitude in Wistar rats $(70 \pm 9 \%$ over baseline, $n=5)$ and recovered the depressed LTP amplitude in GK rats to near control values ( $74 \pm 5 \%$ over baseline, $n=6)$. A two-way ANOVA on LTP amplitude results showed a significant effect of diabetes $\left[F_{(1,18)}=5.0 ; P=0.038\right]$, no effect of applied drug $\left[F_{(1,18)}=0.5 ; P=0.496\right]$, and a significant effect of their interaction $\left[F_{(1,18)}=9.0 ; P=0.008\right]$. Post-hoc analyses confirmed that LTP amplitude was decreased in GK compared to Wistar rats $(P=0.002)$, whereas SCH58261 recovered plasticity in GK rats $(P=0.014)$ but had a negligible effect in Wistar rats $(P=0.136)$.

\section{DISCUSSION}

The present study deepens our knowledge of the impact of T2D on cognitive function, which is not yet fully understood (Frisardi et al., 2010; Steculorum et al., 2014; Duarte, 2015). Diabetic rats displayed impaired hippocampal-dependent spatial memory, as suggested by reduced Y-maze spontaneous alternation. This diabetes-induced memory impairment was not accompanied by a modification of glucose transport to consumption ratio, that is, there was no alteration of hippocampal glucose concentration at a given glycaemia. Instead, when compared to controls, GK rats displayed alterations of the metabolic profile, synaptic dysfunction, and astrogliosis in the hippocampus. The causal relation between synaptic damage and astrogliosis and the memory impairment in GK rats is further emphasized by the observation that caffeine consumption had simultaneous beneficial effects on diabetes-induced spatial memory dysfunction, synaptic damage, and astrogliosis. We 


\section{Nerve terminal-enriched membranes}
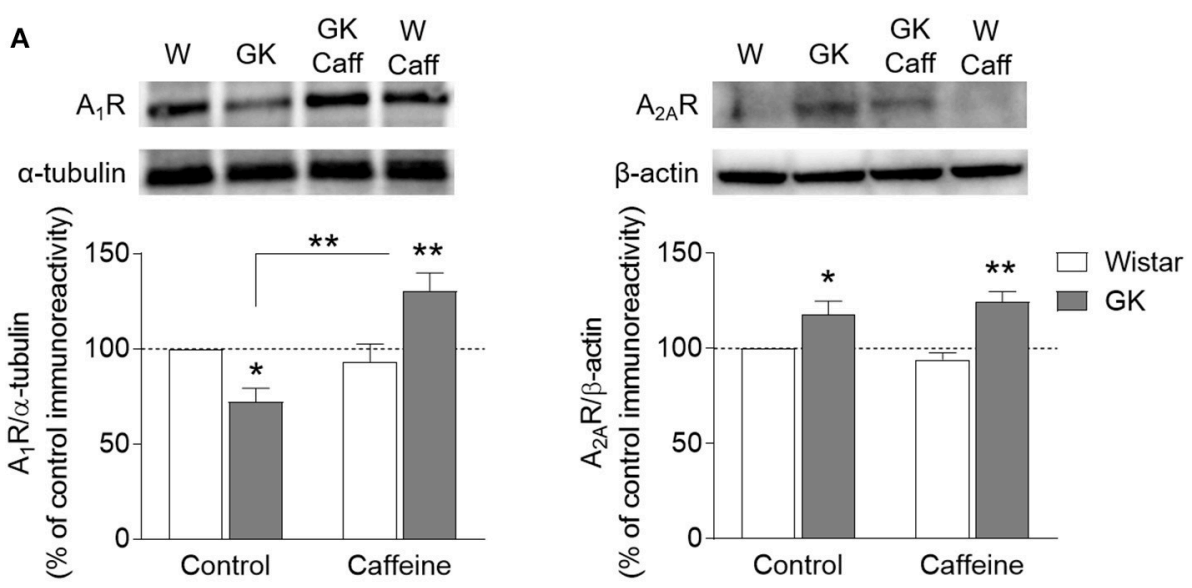

\section{Total membranes}
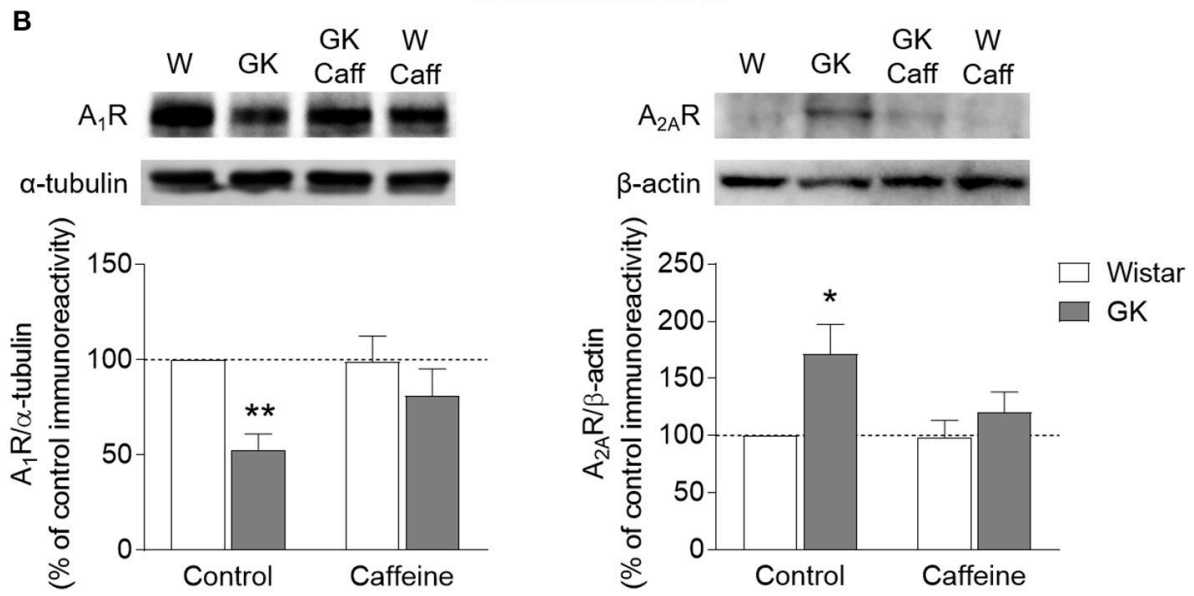

FIGURE 6 | Density $A_{1} R$ and $A_{2 A} R$ analyzed by Western blot in nerve terminal-enriched membranes (A) and total membranes (B) from the hippocampus of GK and Wistar (W) rats, either receiving $1 \mathrm{~g} / \mathrm{L}$ caffeine (Caff) or tap water. Samples were loaded in SDS-PAGE gels at a protein concentration of 40 or $150 \mu \mathrm{g}$ for $\mathrm{A}_{1} \mathrm{R}$ ( $\left.n=6-8\right)$ and $A_{2 A} R(n=2-3)$, respectively. Immunoreactivity was normalized to either $\alpha$-tubulin or $\beta$-actin, and calculated as percentage of control in the same Western blot experiment. Symbols represent LSD test results after ANOVA with either significant diabetes effect or significant diabetes-caffeine interaction: ${ }^{\star} P<0.05$, ${ }^{\star \star} P<0.01$ for GK vs. Wistar in the respective treatment group or as indicated.

further observed that both caffeine and T2D have an impact on metabolism in the hippocampus. However, caffeine consumption did not prevent diabetes-induced metabolic changes. It remains to be ascertained whether caffeine-associated metabolic changes are beneficial for the diabetic brain.

Brain function relies on glucose as main source of energy, and resting brain glucose uptake and consumption are largely independent from circulating insulin (Hasselbalch et al., 1999). Although diabetes leads to inadequate glucose transport in peripheral tissues, brain glucose utilization may eventually adapt to a new metabolic condition upon diabetes (Pelligrino et al., 1992). Some studies reported a lack of effect of type 1 diabetes on the transport of glucose into the brain (Kainulainen et al., 1993; Simpson et al., 1999). Likewise, previous studies in humans reported that poorly controlled diabetes did not affect glucose transport into the brain (Fanelli et al., 1998). We have previously found that insulin-dependent rats have hippocampus to plasma glucose concentrations similar to controls (Duarte et al., 2009a). In GK rats, we recently demonstrated that T2D is associated to reduced glucose transport and consumption rates in the whole brain, without modifying brain to plasma glucose relationship at steady-state. The present results confirmed this observation in the dorsal hippocampus, which controls learning and memory. Unaltered glucose transport to consumption ratio $\left(\mathrm{T}_{\max } / \mathrm{CMR}_{\mathrm{glc}}\right)$ implies an increased glucose concentration in the hippocampus under sustained hyperglycaemia. The high glucose level in the hippocampus may trigger osmolarity alterations and thus induce metabolic adaptation. This is expected to translate into a modified neurochemical profile, as was observed in the hippocampus of GK rats compared to 
A

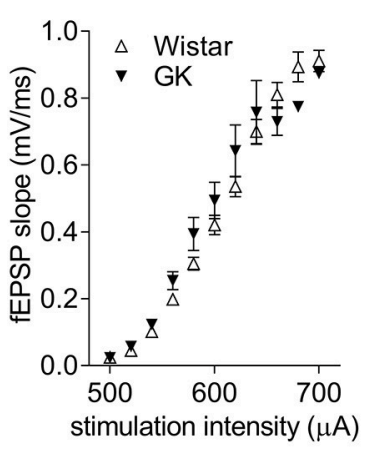

D

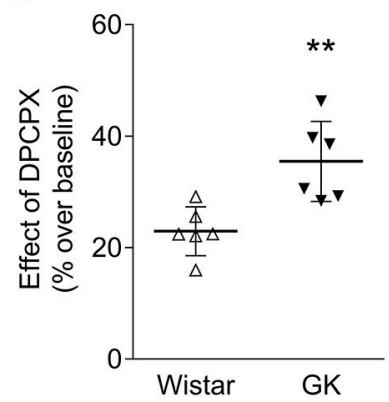

B

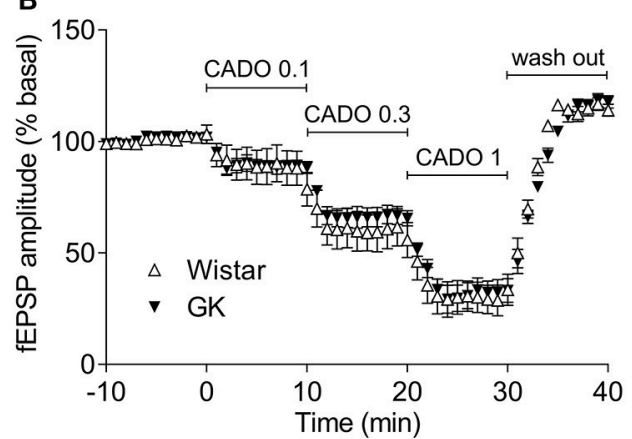

E

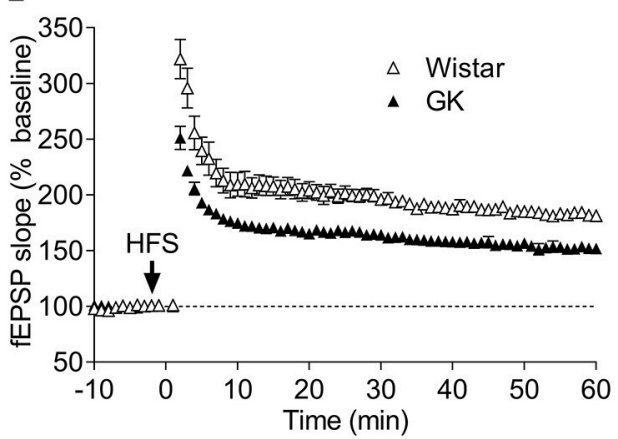

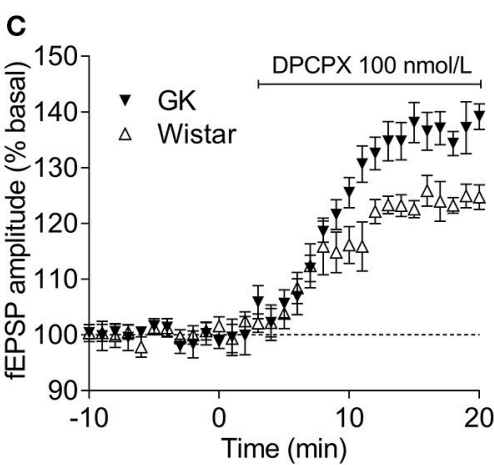

F

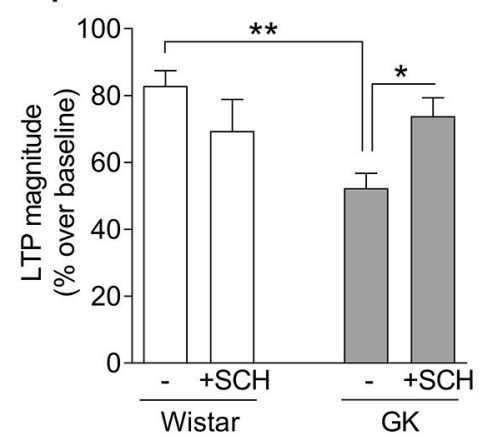

FIGURE 7 | GK rats display an unchanged $A_{1}$ R-mediated inhibition of excitatory synaptic transmission in the hippocampus but an increased $A_{2}$ R-mediated control of synaptic plasticity. (A) Superimposed input-output curves in GK (filed symbols) and Wistar rats (open symbols), indicating a similar density of excitatory innervation in Schaffer fiber-CA1 pyramid synapses of hippocampal slices. (B) Superimposable concentration-dependent curves of inhibition of CA1 hippocampal field excitatory post-synaptic potentials (fEPSPs) by the closest chemical analog of adenosine, 2 -chloroadenosine (CADO; applied at concentrations of 0.1 , 0.3, and $1 \mu$ mol/L), showing that the $A_{1}$ R-mediated inhibition of synaptic transmission is similar in GK and Wistar rats. The fEPSP slope before CADO application is normalized to $100 \%$, and $0 \%$ corresponds to a complete inhibition of fEPSPs. (C,D) GK rats seem to have higher levels of endogenous extracellular adenosine tonically activating inhibitory $A_{1} R$, as revealed by the larger disinhibition of fEPSPs by the selective $A_{1} R$ antagonist, DPCPX. (E) Averaged time course changes of fEPSP slope induced by a high-frequency stimulation train (HFS $100 \mathrm{~Hz}, 1 \mathrm{~s}$, applied when indicated by the arrow) in hippocampal slices taken from Wistar (open symbols) or GK rats (filed symbols), showing that the amplitude of LTP is larger in Wistar than in GK rats. (F) The presence of the $\mathrm{A}_{2 \mathrm{~A}} \mathrm{R}$ antagonist SCH58261 (50 nM, $+\mathrm{SHC}$ ), which was applied $30 \mathrm{~min}$ before LTP induction and remained in the bath up to the end of the experiment, has a discrete effect in Wistar rats (open bars) and efficiently restores LTP amplitude back to control levels in GK rats (gray bars). The electrophysiological data are mean \pm SEM of 5-6 animals per experimental condition. ${ }^{\star} P<0.05$, ${ }^{\star \star} P<0.01$ using either an unpaired Student's $t$ test in $\mathbf{( C )}$ or a two-way ANOVA followed by a LSD post-hoc test in (F).

controls under normoglycaemia (Figure 3). The most prominent alteration was an increase in the hippocampal concentration of the osmolite taurine. Surprisingly, the concentration of myo-inositol (another osmolite) was not substantially altered in the hippocampus of GK rats in the absence of caffeine, in contrast to what was observed in streptozotocin-induced diabetic rats (Duarte et al., 2009a) or Zucker diabetic obese rats (van der Graaf et al., 2004). However, these models of diabetes are characterized by sustained hyperglycaemia ranging from 25 to $30 \mathrm{mM}$ of plasma glucose (Wilkes et al., 2005; Duarte et al., 2009a), while GK rats are subjected to a rather mild hyperglycaemia state (below $15 \mathrm{mmol} / \mathrm{L}$ ). This tentatively suggests that myo-inositol levels may only increase upon more extreme hyperosmolarity.

T2D was also associated with increased levels of ascorbate in the hippocampus, which is in line with stimulation of ascorbate production in the rat liver under mild hyperglycaemia (Küstermann et al., 1998). Ascorbate is involved in the regulation of brain glycolysis and pentose phosphate pathway, as well as astrocyte-neuron metabolic interactions (Cisternas et al., 2014), and changes of its concentration in the hippocampus may be related with T2D-induced adaptations of energy metabolism (Girault et al., 2018). The non-deleterious but rather adaptive nature of these diabetic-induced metabolic changes in hippocampal metabolic profile is supported by the observation that GK rats at euglycaemia displayed augmented phosphocreatine-to-creatine ratio, compared to controls.

As previously observed in the hippocampus of insulindependent diabetic rats, caffeine consumption lowered myoinositol concentration, and increased hippocampal levels of taurine. Taurine is an amino acid that, although present at $1 \mu \mathrm{mol} / \mathrm{g}$ in the human brain, it reaches relatively large concentrations in the rodent brain (above $5 \mu \mathrm{mol} / \mathrm{g}$ in rats and above $8 \mu \mathrm{mol} / \mathrm{g}$ in mice; Duarte, 2016), playing a major role as osmolyte (Duarte et al., 2009a, and references therein). Indeed, caffeine is able to control osmotic swelling via adenosine 
receptors (Wurm et al., 2008). In addition, taurine acts as an agonist at receptors of the GABAergic and glycinergic neurotransmitter systems (Albrecht and Schousboe, 2005), and caffeine controls taurine release from both neurons and glia via adenosine receptors (Hada et al., 1998). Taurine is transported into the mitochondrial matrix where it buffers $\mathrm{pH}$ to the optimal value for isocitrate dehydrogenase, which is a key enzyme of the tricarboxylic acid cycle regulating metabolism and oxidative phosphorylation, contributes to stabilize the $\mathrm{pH}$ gradient across the inner-membrane, and thus helps preserving mitochondrial function and preventing oxidative damage (Hansen et al., 2010). Therefore, this caffeine-associated increase of taurine levels in the diabetic hippocampus is likely related to neuroprotective functions.

Finally, it should be stressed that these adaptive metabolic modifications in the hippocampus of GK rats indeed seem to be caused by hyperglycaemia rather than by hyperinsulinemia since chronic consumption of caffeine prevented the later but not the former, and failed to prevent hippocampal metabolite alterations in GK rats, despite caffeine-induced metabolic changes.

The evaluation of hippocampal metabolite concentrations in Wistar and GK rats showed that this brain structure faces high glucose levels in diabetes at their fed glycaemia, which may lead to neurotoxicity and cellular damage. The present results indicate that $\mathrm{T} 2 \mathrm{D}$ in $\mathrm{GK}$ rats caused neurodegeneration that does not affect the entire neuron, as suggested by unaltered MAP2 immunoreactivity, but instead occurs selectively at the presynaptic component of the nerve terminal, as previously proposed (Duarte et al., 2006, 2009a, 2012; Gaspar et al., 2010). In fact, GK rats displayed a reduced density of the presynaptic proteins SNAP25 and synaptophysin in the hippocampus, whereas the density of the postsynaptic protein PSD95 was not significantly altered relative to controls. The alteration of these presynaptic markers allowed sustaining synaptic transmission but was associated with an alteration of synaptic plasticity typified by a reduced amplitude of long-term potentiation in the hippocampal CA1 area of GK compared to Wistar rats. These synaptic modifications may eventually underlie the memory impairment observed in GK rats, as proposed to occur in Alzheimer's disease-associated neurodegeneration (Selkoe, 2002; Coleman et al., 2004). Together with synaptic dysfunction, we further found increased immunoreactivity of the glial-specific proteins GFAP and vimentin in the hippocampus of GK rats. This is in accordance with the occurrence of astrocytosis in the hippocampus, which was observed in other animal models of diabetes (e.g., Saravia et al., 2002; Baydas et al., 2003; Duarte et al., 2009a, 2012). Astrocytosis can be triggered by neuronal damage and contribute to further neuronal deterioration through the production of free radicals (e.g., Chao et al., 1996) and apoptotic factors (e.g., Crutcher et al., 1993; Fahnestock et al., 1996), leading to memory impairment (see Halassa and Haydon, 2010). In line with synaptic degeneration and astrocytosis, we have previously reported that GK rats show whole brain depression of neuronal oxidative metabolism and glutamate-glutamine cycle, and exacerbation of oxidative metabolism in astrocytes (Girault et al., 2018).
The relation between synaptotoxicity and astrogliosis with memory impairment in GK rats was further supported by the common ability of chronic caffeine consumption to simultaneously ameliorate or prevent these T2D-induced modifications. This is in agreement with the general neuroprotective action of chronic caffeine consumption against brain damage, which is largely mimicked by antagonists of adenosine $\mathrm{A}_{2 \mathrm{~A}}$ Rs (Cunha, 2005; Chen et al., 2007). In particular, both caffeine and selective $\mathrm{A}_{2 \mathrm{~A}} \mathrm{R}$ antagonists are effective in improving memory performance upon noxious insults (Takahashi et al., 2008; Cunha, 2016), which was also observed in this study. Thus, neuroprotection and preservation of memory function by caffeine is likely associated with antagonism of $\mathrm{A}_{2 \mathrm{~A}}$ Rs at the synaptic level as well as in glial cells (Cunha, 2016). Notably, the over-functioning of $\mathrm{A}_{2 \mathrm{~A}} \mathrm{Rs}$ is sufficient to impair memory performance (Li et al., 2015; Pagnussat et al., 2015). Accordingly, $\mathrm{A}_{2 \mathrm{~A}} \mathrm{Rs}$ were up-regulated in the hippocampus of GK rats, similarly to what was observed in other animal models of T1D (Duarte et al., 2009a) or T2D (Duarte et al., 2012) and in a variety of conditions associated with memory dysfunction, such as aging (Rebola et al., 2003; Canas et al., 2009a; Temido-Ferreira et al., 2018) or Alzheimer's disease (Canas et al., 2009b; Espinosa et al., 2013; Viana da Silva et al., 2016; Silva et al., 2018). In fact, the only established molecular targets for caffeine at non-toxic concentrations, which were achieved in the present study, are adenosine receptors, mainly $\mathrm{A}_{1}$ Rs and $\mathrm{A}_{2 \mathrm{~A}}$ Rs (Fredholm et al., 1999). Hippocampal $A_{2 A}$ Rs are concentrated in synapses, where they selectively control synaptic plasticity processes (Rebola et al., 2008; Costenla et al., 2011; Temido-Ferreira et al., 2018) and play a prominent role in controlling the synaptic damage (Cunha et al., 2006; Silva et al., 2007, 2018; Canas et al., 2009b; Viana da Silva et al., 2016) that tightly correlates with memory impairment for instance in Alzheimer's disease (Selkoe, 2002; Coleman et al., 2004). Interestingly, we found that caffeine prevented the diabetes-induced loss of SNAP25 but not of synaptophysin. This is in agreement with previous observations suggesting that proteins of the SNARE complex are more robust indicators of synaptic dysfunction than proteins located in synaptic vesicles, such as synaptophysin (Reddy et al., 2005; Gao et al., 2006). We also observed that $G K$ rats displayed a reduction of $A_{1} R$ immunoreactivity. This was not associated with a modification of $\mathrm{A}_{1} \mathrm{R}$ function controlling basal synaptic transmission in GK rats, in accordance with our observation that the modification of $A_{1} R$ density mostly occurs in total membranes. Since extra-synaptic $\mathrm{A}_{1}$ Rs have recently been associated with modified information processing in cortical circuits (Florian et al., 2011; Serchov et al., 2015), future studies should focus on the possible role of $\mathrm{A}_{1}$ Rs on memory performance through a control of neuron-glia communication.

In whole hippocampal membranes we observed a diabetesinduced reduction in $A_{1} R$ and increase of $A_{2 A} R$ levels, which was normalized upon caffeine treatment. Therefore, limiting excessive activation of $\mathrm{A}_{2 \mathrm{~A}} \mathrm{Rs}$ in extra-synaptic compartments, namely in glial cells, might also be a mechanism of neuroprotection by caffeine in T2D (Cunha, 2016). Indeed, apart from its synapto-protective action, caffeine had beneficial effects on T2D-induced astrogliosis, which emphasizes the 
potential neuroprotective role of glial $\mathrm{A}_{2 \mathrm{~A}}$ Rs (Daré et al., 2007), as reported in animal models of Alzheimer's (Matos et al., 2012) and Parkinson's disease (Yu et al., 2008), as well as exposure to LPS (Rebola et al., 2011) or glaucoma (Madeira et al., 2015).

It is important to stress that the present results do not exclude the possibility that the beneficial effects of chronic caffeine consumption might also involve the control of peripheral metabolism and circulating insulin concentration, such as via adenosine receptors in the pancreatic islet (e.g., Johansson et al., 2007; Töpfer et al., 2008; Salehi et al., 2009), or via regulation of peripheral metabolic rates and energy expenditure (van Dam and Hu, 2005; Greenberg et al., 2006; Higdon and Frei, 2006). It is of interest to note that GK rats chronically consuming caffeine displayed hyperglycemia but not hyperinsulinemia. The chronic caffeine treatment used in the present study was also previously found to improve peripheral insulin sensitivity and reduce circulating insulin concentration in aged rats (Guarino et al., 2013) and rats under diets rich in sugar or fat (Conde et al., 2012). In the brain, insulin and insulin-like growth factor 1 (IGF1) may be involved in regulating the presence of glucose carriers at the membrane of astrocytes (Fernandez et al., 2017), the expression of synaptic proteins and number of synapses (Chiu et al., 2008), the reactivity of astrocytes (e.g., Wilczak and De Keyser, 1997), and learning and memory processes (Zhao and Alkon, 2001). Notably, while insulin and insulin-sensitizing drugs have beneficial effect in dementia, it has also been proposed that persistent activation of insulin receptors could be the trigger for brain insulin resistance (e.g., Mullins et al., 2017). Therefore, further research is needed to understand the role of insulin in T2D-induced brain dysfunction.

In summary, long-term caffeine intake improved T2Dinduced memory impairment, prevented astrogliosis, and ameliorated hippocampal synaptic degeneration in GK rats.

\section{REFERENCES}

Albrecht, J., and Schousboe, A. (2005). Taurine interaction with neurotransmitter receptors in the CNS: an update. Neurochem. Res. 30, 1615-1621. doi: 10.1007/s11064-005-8986-6

Anderson, W. W., and Collingridge, G. L. (2001). The LTP Program: a data acquisition program for on-line analysis of long-term potentiation and other synaptic events. J. Neurosci. Methods. 108, 71-83. doi: 10.1016/S0165-0270(01)00374-0

Baydas, G., Nedzvetskii, V. S., Tuzcu, M., Yasar, A., and Kirichenko, S. V. (2003). Increase of glial fibrillary acidic protein and S-100B in hippocampus and cortex of diabetic rats: effects of vitamin E. Eur. J. Pharmacol. 462, 67-71. doi: 10.1016/S0014-2999(03)01294-9

Canas, P. M., Duarte, J. M. N., Rodrigues, R. J., Köfalvi, A., and Cunha, R. A. (2009a). Modification upon aging of the density of presynaptic modulation systems in the hippocampus. Neurobiol. Aging 30, 1877-1884. doi: 10.1016/j.neurobiolaging.2008.01.003

Canas, P. M., Porciúncula, L. O., Cunha, G. M., Silva, C. G., Machado, N. J., Oliveira, J. M., et al. (2009b). Adenosine $\mathrm{A}_{2 \mathrm{~A}}$ receptor blockade prevents synaptotoxicity and memory dysfunction caused by $\beta$-amyloid peptides via p38 mitogen-activated protein kinase pathway. J. Neurosci. 29, 14741-14751. doi: 10.1523/JNEUROSCI.3728-09.2009

Chao, C. C., Hu, S., Sheng, W. S., Bu, D., Bukrinsky, M. I., and Peterson, P. K. (1996). Cytokine-stimulated astrocytes damage human neurons via a nitric oxide mechanism. Glia 16, 276-284. doi: 10.1002/(SICI)10981136(199603)16:3<276::AID-GLIA10>3.0.CO;2-X
Caffeine did not prevent T2D-associated metabolic modifications in the hippocampus. Nevertheless, it had an impact on metabolite concentrations in the hippocampus of both Wistar and GK rats.

Therefore, we conclude that the hippocampus is adaptable to different metabolic conditions, and that synaptic degeneration and astrogliosis rather than metabolic modifications contribute to diabetes-induced memory dysfunction. Finally, the present study also emphasizes the neuroprotective potential of chronic caffeine consumption as a prophylactic strategy to prevent memory impairment in T2D.

\section{AUTHOR CONTRIBUTIONS}

JD and RC designed the study. JD, CS, and HS performed experiments and analyzed data. JD wrote the manuscript. All authors contributed to the interpretation of the results and revised the manuscript.

\section{ACKNOWLEDGMENTS}

This work was supported by the Knut and Alice Wallenberg Foundation, Swedish Research Council (Strategic Research Area EXODIAB, grant 2009-1039), Swedish Foundation for Strategic Research (grant IRC15-0067), Swiss National Science Foundation (Ambizione grant 148250), Fundação para a Ciência e a Tecnologia (grants POCTI/SAU-NEU/56098/2004 and POCI-01-0145-FEDER-031274), Centro 2020 (projects CENTRO-01-0145-FEDER-000008:BrainHealth 2020 and CENTRO-01-0246-FEDER-000010), and Center d'Imagerie BioMédicale (CIBM) of the UNIL, UNIGE, HUG, CHUV, EPFL, and the Leenaards and Jeantet Foundations. We thank Professor Raquel Seiça for supplying brain tissue from some Wistar and GK rats.

Chen, J. F., Sonsalla, P. K., Pedata, F., Melani, A., Domenici, M. R., Popoli, P., et al. (2007). Adenosine $A_{2 A}$ receptors and brain injury: broad spectrum of neuroprotection, multifaceted actions and "fine tuning" modulation. Prog. Neurobiol. 83, 310-331. doi: 10.1016/j.pneurobio.2007.09.002

Chiu, S. L., Chen, C. M., and Cline, H. T. (2008). Insulin receptor signaling regulates synapse number, dendritic plasticity, and circuit function in vivo. Neuron 58, 708-719. doi: 10.1016/j.neuron.2008.04.014

Cisternas, P., Silva-Alvarez, C., Martínez, F., Fernandez, E., Ferrada, L., Oyarce, K., et al. (2014). The oxidized form of vitamin C, dehydroascorbic acid, regulates neuronal energy metabolism. J. Neurochem. 129, 663-671. doi: $10.1111 /$ jnc. 12663

Coleman, P., Federoff, H., and Kurlan, R. (2004). A focus on the synapse for neuroprotection in Alzheimer disease and other dementias. Neurology 63, 1155-1162. doi: 10.1212/01.WNL.0000140626.48 $118.0 \mathrm{~A}$

Conde, S. V., Nunes da Silva, T., Gonzalez, C., Mota Carmo, M., Monteiro, E. C., and Guarino, M. P. (2012). Chronic caffeine intake decreases circulating catecholamines and prevents diet-induced insulin resistance and hypertension in rats. Br. J. Nutr. 107, 86-95. doi: 10.1017/S00071145110 02406

Convit, A., Wolf, O. T., Tarshish, C., and de Leon, M. J. (2003). Reduced glucose tolerance is associated with poor memory performance and hippocampal atrophy among normal elderly. Proc. Natl. Acad. Sci. U.S.A. 100, 2019-2022. doi: 10.1073/pnas. 0336073100

Costenla, A. R., Diógenes, M. J., Canas, P. M., Rodrigues, R. J., Nogueira, C., Maroco, J., et al. (2011). Enhanced role of adenosine $A_{2 A}$ receptors in the 
modulation of LTP in the rat hippocampus upon ageing. Eur. J. Neurosci. 34, 12-21. doi: 10.1111/j.1460-9568.2011.07719.x

Crutcher, K. A., Scott, S. A., Liang, S., Everson, W. V., and Weingartner, J. (1993). Detection of NGF-like activity in human brain tissue: increased levels in Alzheimer's disease. J. Neurosci. 13, 2540-2550. doi: 10.1523/JNEUROSCI.13-06-02540.1993

Cunha, G. M., Canas, P. M., Oliveira, C. R., and Cunha, R. A. (2006). Increased density and synapto-protective effect of adenosine $A_{2 A}$ receptors upon sub-chronic restraint stress. Neuroscience 141, 1775-1781. doi: 10.1016/j.neuroscience.2006.05.024

Cunha, R. A. (2005). Neuroprotection by adenosine in the brain: from $A_{1}$ receptor activation to $\mathrm{A}_{2 \mathrm{~A}}$ receptor blockade. Purinergic. Signal. 1, 111-134. doi: 10.1007/s11302-005-0649-1

Cunha, R. A. (2016). How does adenosine control neuronal dysfunction and neurodegeneration? J. Neurochem. 139, 1019-1055. doi: 10.1111/jnc.13724

Daré, E., Schulte, G., Karovic, O., Hammarberg, C., and Fredholm, B. B. (2007). Modulation of glial cell functions by adenosine receptors. Physiol. Behav. 92, 15-20. doi: 10.1016/j.physbeh.2007.05.031

Duarte, J. M.(2015). Metabolic alterations associated to brain dysfunction in diabetes. Aging Dis. 6, 304-321. doi: 10.14336/AD.2014.1104

Duarte, J. M., Carvalho, R. A., Cunha, R. A., and Gruetter, R. (2009a). Caffeine consumption attenuates neurochemical modifications in the hippocampus of streptozotocin-induced diabetic rats. J. Neurochem. 111, 368-379. doi: $10.1111 / j .1471-4159.2009 .06349 . x$

Duarte, J. M., and Gruetter, R. (2012). Characterization of cerebral glucose dynamics in vivo with a four-state conformational model of transport at the blood-brain barrier. J. Neurochem. 121, 396-406. doi: 10.1111/j.1471-4159.2012.07688.x

Duarte, J. M., Morgenthaler, F. D., Lei, H., Poitry-Yamate, C., and Gruetter, R. (2009b). Steady-state brain glucose transport kinetics re-evaluated with a four-state conformational model. Front. Neuroenergetics 1:6. doi: 10.3389/neuro.14.006.2009

Duarte, J. M., Oses, J. P., Rodrigues, R. J., and Cunha, R. A. (2007). Modification of purinergic signaling in the hippocampus of streptozotocin-induced diabetic rats. Neuroscience 149, 382-391. doi: 10.1016/j.neuroscience.2007.08.005

Duarte, J. M. N. (2016). Metabolism in the diabetic brain: neurochemical profiling by ${ }^{1} \mathrm{H}$ magnetic resonance spectroscopy. J. Diabetes. Metab. Disord. 3:011. doi: 10.24966/DMD-201X/100011

Duarte, J. M. N., Agostinho, P. M., Carvalho, R. A., and Cunha, R. A. (2012). Caffeine consumption prevents diabetes-induced memory impairment and synaptotoxicity in the hippocampus of NONcNZO10/LtJ mice. PLoS ONE 7:e21899. doi: 10.1371/journal.pone.0021899

Duarte, J. M. N., Oliveira, C. R., Ambrósio, A. F., and Cunha, R. A. (2006). Modification of adenosine $A_{1}$ and $A_{2 A}$ receptor density in the hippocampus of streptozotocin-induced diabetic rats. Neurochem. Int. 48, 144-150. doi: 10.1016/j.neuint.2005.08.008

Espinosa, J., Rocha, A., Nunes, F., Costa, M. S., Schein, V., Kazlauckas, V., et al. (2013). Caffeine consumption prevents memory impairment, neuronal damage and adenosine $\mathrm{A}_{2 \mathrm{~A}}$ receptors up-regulation in the hippocampus of a rat model of sporadic dementia. J. Alzheimer. Dis. 34, 509-518. doi: 10.3233/JAD-111982

Fahnestock, M., Scott, S. A., Jetté, N., Weingartner, J. A., and Crutcher, K. A. (1996). Nerve growth factor mRNA and protein levels measured in the same tissue from normal and Alzheimer's disease parietal cortex. Mol. Brain Res. 42, 175-178. doi: 10.1016/S0169-328X(96)00193-3

Fanelli, C. G., Dence, C. S., Markham, J., Videen, T. O., Paramore, D. S., Cryer, P. E., et al. (1998). Blood-to-brain glucose transport and cerebral glucose metabolism are not reduced in poorly controlled type 1 diabetes. Diabetes 47, 1444-1450. doi: 10.2337/diabetes.47.9.1444

Fernandez, A. M., Hernandez-Garzón, E., Perez-Domper, P., Perez-Alvarez, A., Mederos, S., Matsui, T., et al. (2017). Insulin regulates astrocytic glucose handling through cooperation with IGF-I. Diabetes 66, 64-74. doi: $10.2337 / \mathrm{db} 16-0861$

Florian, C., Vecsey, C. G., Halassa, M. M., Haydon, P. G., and Abel, T. (2011). Astrocyte-derived adenosine and $\mathrm{A}_{1}$ receptor activity contribute to sleep lossinduced deficits in hippocampal synaptic plasticity and memory in mice. $J$. Neurosci. 31, 6956-6962. doi: 10.1523/JNEUROSCI.5761-10.2011

Fredholm, B. B., Bättig, K., Holmén, J., Nehlig, A., and Zvartau, E. E. (1999). Actions of caffeine in the brain with special reference to factors that contribute to its widespread use. Pharmacol. Rev. 51, 83-133.
Frisardi, V., Solfrizzi, V., Seripa, D., Capurso, C., Santamato, A., Sancarlo, D., et al. (2010). Metabolic-cognitive syndrome: a cross-talk between metabolic syndrome and Alzheimer's disease. Ageing Res. Rev. 9, 399-417. doi: 10.1016/j.arr.2010.04.007

Gao, Y., Bezchlibnyk, Y. B., Sun, X., Wang, J. F., McEwen, B. S., and Young, L. T. (2006). Effects of restraint stress on the expression of proteins involved in synaptic vesicle exocytosis in the hippocampus. Neuroscience 141, 1139-1148. doi: 10.1016/j.neuroscience.2006.04.066

Gaspar, J. M., Baptista, F. I., Galvão, J., Castilho, A. F., Cunha, R. A., and Ambrósio, A. F. (2010). Diabetes differentially affects the content of exocytotic proteins in hippocampal and retinal nerve terminals. Neuroscience 169, 1589-1600. doi: 10.1016/j.neuroscience.2010.06.021

Girault, F. M., Sonnay, S., Gruetter, R., and Duarte, J. M. N. (2018). Alterations of brain energy metabolism in type 2 diabetic Goto-Kakizaki rats measured in vivo by ${ }^{13} \mathrm{C}$ magnetic resonance spectroscopy. Neurotox. Res. doi: 10.1007/s12640-017-9821-y. [Epub ahead of print].

Gold, S. M., Dziobek, I., Sweat, V., Tirsi, A., Rogers, K., Bruehl, H., et al. (2007). Hippocampal damage and memory impairments as possible early brain complications of type 2 diabetes. Diabetologia 50, 711-719. doi: 10.1007/s00125-007-0602-7

Greenberg, J. A., Boozer, C. N., and Geliebter, A. (2006). Coffee, diabetes, and weight control. Am. J. Clin. Nutr. 84, 682-693. doi: 10.1093/ajcn/84.4.682

Gruetter, R., and Tkáč, I. (2000). Field mapping without reference scan using asymmetric echo-planar techniques. Magn. Reson. Med. 43, 319-323. doi: 10. 1002/(SICI) 1522-2594(200002)43:2<319::AID-MRM22>3.0.CO;2-1

Guarino, M. P., Ribeiro, M. J., Sacramento, J. F., and Conde, S. V. (2013). Chronic caffeine intake reverses age-induced insulin resistance in the rat: effect on skeletal muscle Glut4 transporters and AMPK activity. Age (Dordr) 35, 1755-1765. doi: 10.1007/s11357-012-9475-x

Hada, J., Kaku, T., Morimoto, K., Hayashi, Y., and Nagai, K. (1998). Activation of adenosine $\mathrm{A}_{2}$ receptors enhances high $\mathrm{K}^{+}$-evoked taurine release from rat hippocampus: a microdialysis study. Amino Acids 15, 43-52. doi: 10.1007/BF01345279

Halassa, M. M., and Haydon, P. G. (2010). Integrated brain circuits: astrocytic networks modulate neuronal activity and behavior. Annu. Rev. Physiol. 72, 335-355. doi: 10.1146/annurev-physiol-021909-135843

Hansen, S. H., Andersen, M. L., Cornett, C., Gradinaru, R., and Grunnet, N. (2010). A role for taurine in mitochondrial function. J. Biomed. Sci. 17:S23. doi: 10.1186/1423-0127-17-S1-S23

Hasselbalch, S. G., Knudsen, G. M., Videbaek, C., Pinborg, L. H., Schmidt, J. F., Holm, S., et al. (1999). No effect of insulin on glucose blood-brain barrier transport and cerebral metabolism in humans. Diabetes 48, 1915-1921. doi: $10.2337 /$ diabetes.48.10.1915

Higdon, J. V., and Frei, B. (2006). Coffee and health: a review of recent human research. Crit. Rev. Food Sci. Nutr. 46, 101-123. doi: 10.1080/10408390500400009

Hurtado-Alvarado, G., Domínguez-Salazar, E., Velázquez-Moctezuma, J., and Gómez-González, B. (2016). A $2 \mathrm{~A}$ Adenosine receptor antagonism reverts the blood-brain barrier dysfunction induced by sleep restriction. PLOS ONE 11:e0167236. doi: 10.1371/journal.pone.0167236

Johansson, S. M., Salehi, A., Sandström, M. E., Westerblad, H., Lundquist, I., Carlsson, P. O., et al. (2007). $A_{1}$ receptor deficiency causes increased insulin and glucagon secretion in mice. Biochem. Pharmacol. 74, 1628-1635. doi: 10.1016/j.bcp.2007.08.006

Kainulainen, H., Schürmann, A., Vilja, P., and Joost, H. G. (1993). in vivo glucose uptake and glucose transporter proteins GLUT1 and GLUT3 in brain tissue from streptozotocin-diabetic rats. Acta Physiol. Scand. 149, 221-225. doi: 10.1111/j.1748-1716.1993.tb09615.x

Kaster, M. P., Machado, N. J., Silva, H. B., Nunes, A., Ardais, A. P., Santana, M., et al. (2015). Caffeine acts through neuronal adenosine $A_{2 A}$ receptors to prevent mood and memory dysfunction triggered by chronic stress. Proc. Natl. Acad. Sci. U.S.A. 112, 7833-7838. doi: 10.1073/pnas.1423088112

Küstermann, E., Seelig, J., and Künnecke, B. (1998). Ascorbic acid, a vitamin, is observed by in vivo ${ }^{13} \mathrm{C}$ nuclear magnetic resonance spectroscopy of rat liver. Am. J. Physiol. 274(1 Pt 1), E65-E71.

Lalonde, R. (2002). The neurobiological basis of spontaneous alternation. Neurosci. Biobehav. Rev. 26, 91-104. doi: 10.1016/S0149-7634(01)00041-0

Li, P., Rial, R., Canas, P. M., Yoo, J. H., Li, W., Zhou, X., et al. (2015). Optogenetic activation of intracellular adenosine $\mathrm{A}_{2 \mathrm{~A}}$ receptor signaling in hippocampus 
is sufficient to trigger CREB phosphorylation and impair memory. Mol. Psychiatry 20, 1339-1349. doi: 10.1038/mp.2014.182

Lopes, L. V., Halldner, L., Rebola, N., Johansson, B., Ledent, C., Chen, J. F., et al. (2004). Binding of the prototypical adenosine $A_{2 A}$ receptor agonist CGS 21680 to the cerebral cortex of adenosine $\mathrm{A}_{1}$ and $\mathrm{A}_{2 \mathrm{~A}}$ receptor knockout mice. $\mathrm{Br}$. J. Pharmacol. 141, 1006-1014. doi: 10.1038/sj.bjp.0705692

Madeira, M. H., Elvas, F., Boia, R., Gonçalves, F. Q., Cunha, R. A., Ambrósio, A. F., et al. (2015). Adenosine $A_{2 A} R$ blockade prevents neuroinflammationinduced death of retinal ganglion cells caused by elevated pressure. $J$. Neuroinflammation 12:115. doi: 10.1186/s12974-015-0333-5

Matos, M., Augusto, E., Machado, N. J., dos Santos-Rodrigues, A., Cunha, R. A., and Agostinho, P. (2012). Astrocytic adenosine $A_{2 A}$ receptors control the amyloid- $\beta$ peptide-induced decrease of glutamate uptake. J. Alzheimers Dis. 31, 555-567. doi: 10.3233/JAD-2012-120469

Mlynárik, V., Gambarota, G., Frenkel, H., and Gruetter, R. (2006). Localized shortecho-time proton MR spectroscopy with full signal-intensity acquisition. Magn. Reson. Med. 56, 965-970. doi: 10.1002/mrm.21043

Moheet, A., Mangia, S., and Seaquist, E. R. (2015). Impact of diabetes on cognitive function and brain structure. Ann. N. Y. Acad. Sci. 1353, 60-71 doi: $10.1111 /$ nyas. 12807

Mullins, R. J., Diehl, T. C., Chia, C. W., and Kapogiannis, D. (2017). Insulin resistance as a link between amyloid-beta and tau pathologies in Alzheimer's disease. Front. Aging Neurosci. 9:118. doi: 10.3389/fnagi.2017.00118

Pagnussat, N., Almeida, A. S., Marques, D. M., Nunes, F., Chenet, G. C., Botton, P. H., et al. (2015). Adenosine $A_{2 A}$ receptors are necessary and sufficient to trigger memory impairment in adult mice. Br. J. Pharmacol. 172, 3831-3845. doi: 10.1111/bph.13180

Pelligrino, D. A., LaManna, J. C., Duckrow, R. B., Bryan, R. M., and Harik, S. I. (1992). Hyperglycemia and blood-brain barrier glucose transport. J. Cereb. Blood Flow Metab. 12, 887-899. doi: 10.1038/jcbfm.1992.126

Rebola, N., Canas, P. M., Oliveira, C. R., and Cunha, R. A. (2005). Different synaptic and subsynaptic localization of adenosine $A_{2 A}$ receptors in the hippocampus and striatum of the rat. Neuroscience 132, 893-903. doi: 10.1016/j.neuroscience.2005.01.014

Rebola, N., Lujan, R., Cunha, R. A., and Mulle, C. (2008). Adenosine $A_{2 A}$ receptors are essential for long-term potentiation of NMDA-EPSCs at hippocampal mossy fiber synapses. Neuron 57, 121-134. doi: 10.1016/j.neuron.2007.11.023

Rebola, N., Sebastião, A. M., de Mendonça, A., Oliveira, C. R., Ribeiro, J. A., and Cunha, R. A. (2003). Enhanced adenosine $A_{2 A}$ receptor facilitation of synaptic transmission in the hippocampus of aged rats. J. Neurophysiol. 90, 1295-1303. doi: $10.1152 /$ in. 00896.2002

Rebola, N., Simões, A. P., Canas, P. M., Tomé, A. R., Andrade, G. M., Barry, C. E., et al. (2011). Adenosine $A_{2 A}$ receptors control neuroinflammation and consequent hippocampal neuronal dysfunction. J. Neurochem. 117, 100-111. doi: 10.1111/j.1471-4159.2011.07178.x

Reddy, P. H., Mani, G., Park, B. S., Jacques, J., Murdoch, G., Whetsell, W., et al. (2005). Differential loss of synaptic proteins in Alzheimer's disease: implications for synaptic dysfunction. J. Alzheimers Dis. 7, 103-117. doi: 10.3233/JAD-2005-7203

Salehi, A., Parandeh, F., Fredholm, B. B., Grapengiesser, E., and Hellman, B. (2009). Absence of adenosine $A_{1}$ receptors unmasks pulses of insulin release and prolongs those of glucagon and somatostatin. Life Sci. 85, 470-476. doi: 10.1016/j.lfs.2009.08.001

Saravia, F. E., Revsin, Y., Gonzalez Deniselle, M. C., Gonzalez, S. L., Roig, P., Lima, A., et al. (2002). Increased astrocyte reactivity in the hippocampus of murine models of type 1 diabetes: the non-obese diabetic (NOD) and streptozotocintreated mice. Brain Res. 957, 345-353. doi: 10.1016/S0006-8993(02)03675-2

Sebastião, A. M., Cunha, R. A., de Mendonça, A., and Ribeiro, J. A. (2000). Modification of adenosine modulation of synaptic transmission in the hippocampus of aged rats. Br. J. Pharmacol. 131, 1629-1634. doi: 10.1038/sj.bjp.0703736

Selkoe, D. J. (2002). Alzheimer's disease is a synaptic failure. Science 298, 789-791. doi: $10.1126 /$ science. 1074069

Serchov, T., Clement, H. W., Schwarz, M. K., Iasevoli, F., Tosh, D. K., Idzko, M., et al. (2015). Increased signaling via adenosine $A_{1}$ receptors, sleep deprivation, imipramine, and ketamine inhibit depressive-like behavior via induction of homerla. Neuron 87, 549-562. doi: 10.1016/j.neuron.2015.07.010
Silva, A. C., Lemos, C., Gonçalves, F. Q., Pliássova, A. V., Machado, N. J., Silva, H. B., et al. (2018). Blockade of adenosine $A_{2 A}$ receptors recovers early deficits of memory and plasticity in the triple transgenic mouse model of Alzheimer's disease. Neurobiol. Dis. 117, 72-81. doi: 10.1016/j.nbd.2018. 05.024

Silva, C. G., Porciúncula, L. O., Canas, P. M., Oliveira, C. R., and Cunha, R. A. (2007). Blockade of adenosine $A_{2 A}$ receptors prevents staurosporineinduced apoptosis of rat hippocampal neurons. Neurobiol. Dis. 27, 182-189. doi: 10.1016/j.nbd.2007.04.018

Simpson, I. A., Appel, N. M., Hokari, M., Oki, J., Holman, G. D., Maher, F., et al. (1999). Blood-brain barrier glucose transporter: effects of hypo- and hyperglycemia revisited. J. Neurochem. 72, 238-247. doi: 10.1046/j.1471-4159.1999.0720238.x

Steculorum, S. M., Solas, M., and Brüning, J. C. (2014). The paradox of neuronal insulin action and resistance in the development of aging-associated diseases. Alzheimers Dement. 10(1 Suppl. ), S3-S11. doi: 10.1016/j.jalz.2013. 12.008

Takahashi, R. N., Pamplona, F. A., and Prediger, R. D. (2008). Adenosine receptor antagonists for cognitive dysfunction: a review of animal studies. Front. Biosci. 13, 2614-2632. doi: 10.2741/2870

Temido-Ferreira, M., Ferreira, D. G., Batalha, V. L., Marques-Morgado, I., Coelho, J. E., Pereira, P., et al. (2018). Age-related shift in LTD is dependent on neuronal adenosine $\mathrm{A}_{2 \mathrm{~A}}$ receptors interplay with mGluR5 and NMDA receptors. Mol. Psychiatry. doi: 10.1038/s41380-018-0110-9. [Epub ahead of print].

Töpfer, M., Burbiel, C. E., Müller, C. E., Knittel, J., and Verspohl, E. J. (2008). Modulation of insulin release by adenosine $A_{1}$ receptor agonists and antagonists in INS-1 cells: the possible contribution of ${ }^{86} \mathrm{Rb}^{+}$efflux and ${ }^{45} \mathrm{Ca}^{2+}$ uptake. Cell Biochem. Funct. 26, 833-843. doi: 10.1002/cbf.1514

van Dam, R. M., and Hu, F. B. (2005). Coffee consumption and risk of type 2 diabetes: a systematic review. JAMA 294, 97-104. doi: 10.1001/jama.294.1.97

van der Graaf, M., Janssen, S. W., van Asten, J. J., Hermus, A. R., Sweep, C. G., Pikkemaat, J. A., et al. (2004). Metabolic profile of the hippocampus of Zucker Diabetic Fatty rats assessed by in vivo ${ }^{1} \mathrm{H}$ magnetic resonance spectroscopy. NMR Biomed. 17, 405-410. doi: 10.1002/nbm.896

Viana da Silva, S., Haberl, M. G., Zhang, P., Bethge, P., Lemos, C., Gonçalves, N., et al. (2016). Early synaptic deficits in the APP/PS1 mouse model of Alzheimer's disease involve neuronal adenosine $\mathrm{A}_{2 \mathrm{~A}}$ receptors. Nature Comm. 7:11915. doi: 10.1038/ncomms11915

Wilczak, N., and De Keyser, J. (1997). Insulin-like growth factor-I receptors in normal appearing white matter and chronic plaques in multiple sclerosis. Brain Res. 772, 243-246. doi: 10.1016/S0006-8993(97)00940-2

Wilkes, J. J., Nelson, E., Osborne, M., Demarest, K. T., and Olefsky, J. M. (2005). Topiramate is an insulin-sensitizing compound in vivo with direct effects on adipocytes in female ZDF rats. Am. J. Physiol. Endocrinol. Metab. 288, E617-E624. doi: 10.1152/ajpendo.00437.2004

Wurm, A., Iandiev, I., Hollborn, M., Wiedemann, P., Reichenbach, A., Zimmermann, H., et al. (2008). Purinergic receptor activation inhibits osmotic glial cell swelling in the diabetic rat retina. Exp. Eye. Res. 87, 385-393. doi: 10.1016/j.exer.2008.07.004

Yu, L., Shen, H. Y., Coelho, J. E., Araújo, I. M., Huang, Q. Y., Day, Y. J., et al. (2008). Adenosine $\mathrm{A}_{2 \mathrm{~A}}$ receptor antagonists exert motor and neuroprotective effects by distinct cellular mechanisms. Ann. Neurol. 63, 338-346. doi: 10.1002/ana.21313

Zhao, W. Q., and Alkon, D. L. (2001). Role of insulin and insulin receptor in learning and memory. Mol. Cell Endocrinol. 177, 125-134. doi: $10.1016 / S 0303-7207(01) 00455-5$

Conflict of Interest Statement: The authors declare that the research was conducted in the absence of any commercial or financial relationships that could be construed as a potential conflict of interest.

Copyright $\odot 2019$ Duarte, Skoug, Silva, Carvalho, Gruetter and Cunha. This is an open-access article distributed under the terms of the Creative Commons Attribution License (CC BY). The use, distribution or reproduction in other forums is permitted, provided the original author(s) and the copyright owner(s) are credited and that the original publication in this journal is cited, in accordance with accepted academic practice. No use, distribution or reproduction is permitted which does not comply with these terms. 